\title{
DEVELOPMENT AND APPLICATION OF PROCEDURES TO EVALUATE AIR QUALTTY AND VISIBILITY IMPACTS OF LOW-ALTTTUDE FLYING OPERATIONS
}

by

E. $\therefore$ Liebsch

Oak Ridge National Laboratory

Oak Ridge, TN 37831

August 1990

Prepared for

Engineering \& Services Laboratory Air Force Engineering \& Services Center

Tyndall Air Force Base, FL 32403

Prepared by the

OAK RIDGE NATIONAL LABORATORY

Oak Ridge, Tennessee 37831 operated by

MARTIN MARIETTA ENERGY SYSTEMS, INC.

for the

U.S. DEPARTMENT OF ENERGY

under Contract No. DE-AC05-84OR21400 


\section{TABLE OF TONTENTS}

LIST OF FIGURES $\ldots \ldots \ldots \ldots \ldots \ldots \ldots \ldots \ldots \ldots \ldots \ldots \ldots$

LIST OF TABLES $\ldots \ldots \ldots \ldots \ldots \ldots \ldots \ldots \ldots \ldots \ldots \ldots \ldots \ldots \ldots \ldots$

PREFACE $\ldots \ldots \ldots \ldots \ldots \ldots \ldots \ldots \ldots \ldots \ldots \ldots \ldots \ldots \ldots \ldots \ldots \ldots \ldots \ldots \ldots \ldots$

LIST OF ABBREVIATIONS AND ACRONYMS $\ldots \ldots \ldots \ldots \ldots \ldots \ldots \ldots$ xi

EXECUTIVE SUMMARY $\ldots \ldots \ldots \ldots \ldots \ldots \ldots \ldots \ldots \ldots \ldots \ldots \ldots \ldots \ldots$ xiii

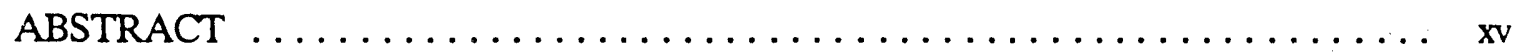

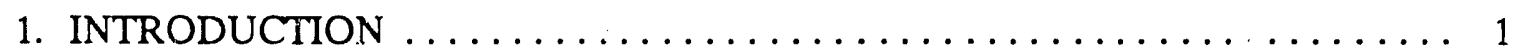

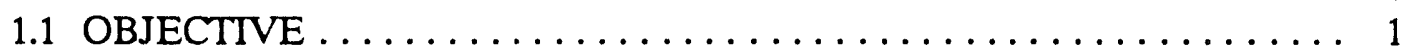

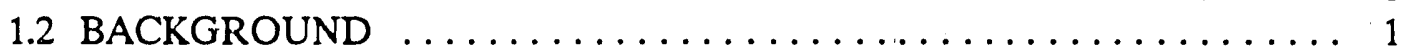

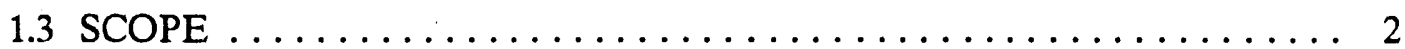

2. METHODS SELECTION AND DEVELOPMENT $\ldots \ldots \ldots \ldots \ldots \ldots \ldots \ldots$

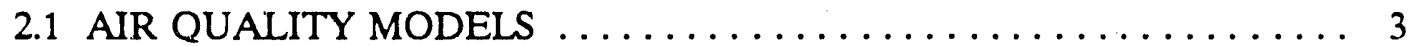

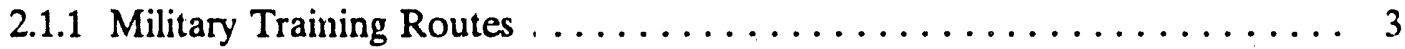

2.1.2 Military Operations and Restricted Areas ................ 3

2.2 VISIBILITY ASSESSMENT PROCEDURES $\ldots \ldots \ldots \ldots \ldots \ldots \ldots$

3. METHODS APPLICATION AND RESULTS $\ldots \ldots \ldots \ldots \ldots \ldots \ldots \ldots \ldots \ldots$

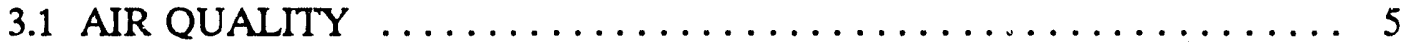

3.1 .1 Military Training Routes ...................... 5

3.1.2 Military Operations and Restricted Areas ................ 5

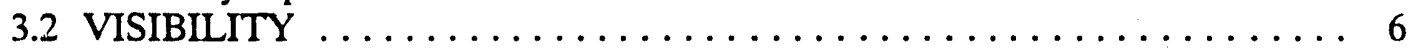

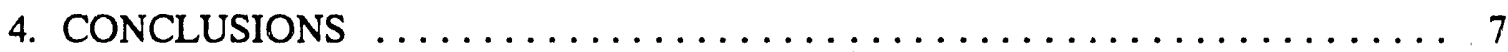

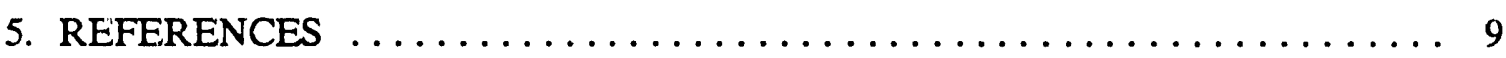

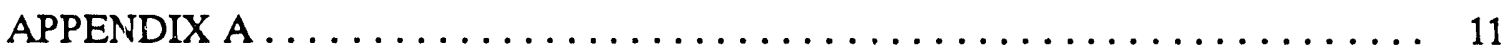

A.1 INTRODUCTION: FRAMING OF THE ISSUES $\ldots \ldots \ldots \ldots \ldots \ldots 13$

A.1.1 Issues Raised in Scoping Process . . . . . . . . . . . . . 13

A.1.2 Regulatory Issues . . . . . . . . . . . . . . . . . . 13

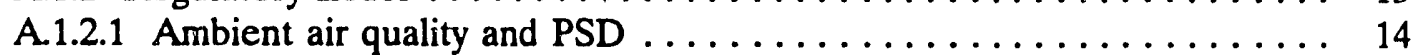

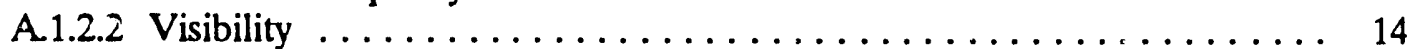

A.2 LITERATURE REVIEW $\ldots \ldots \ldots \ldots \ldots \ldots \ldots \ldots \ldots \ldots \ldots \ldots \ldots$

A.2.1 Ambient Air Quality Impact Assessment . . . . . . . . . . . . . . . 17

A.2.2 Visibility Impact Assessment . . . . . . . . . . . . . . . 18

A.2.3 Findings . . . . . . . . . . . . . . . . . . . . . . 19

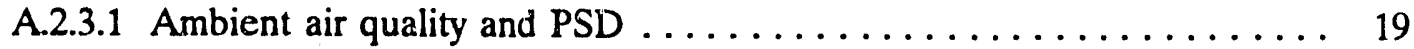

A.2.3.2 Visibility ................................ 19 
TABLE OF CONTENTS (continuec)

A.3 GEIS RESEARCH $\ldots \ldots \ldots \ldots \ldots \ldots \ldots \ldots \ldots \ldots \ldots \ldots \ldots$

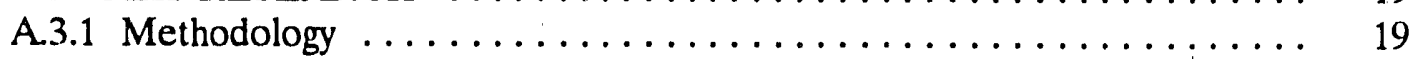

A.3.1.1 Ambient air quality impact assessment ................. 19

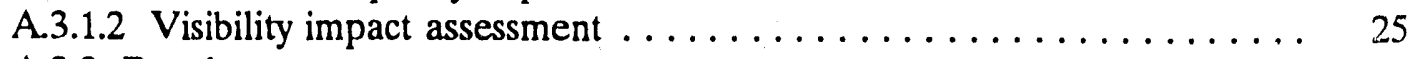

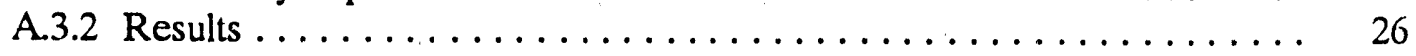

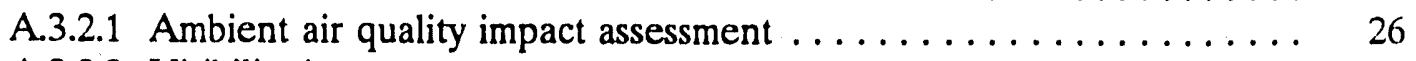

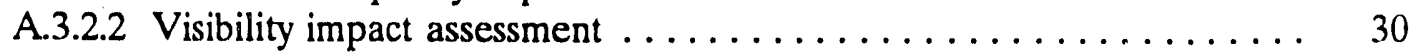

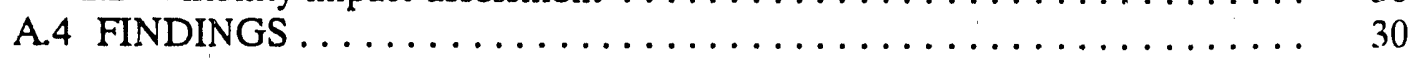

A.4.1 Findings Directed at Impacts and Mitigations ............ 30

A.4.2 Findings Directed at Policy and Planning Intervention $\ldots \ldots \ldots \ldots . \ldots . \ldots 32$

A.4.3 Findings Directed at General Explanations of Impacts ... . . . . . . 32

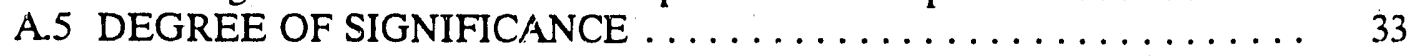

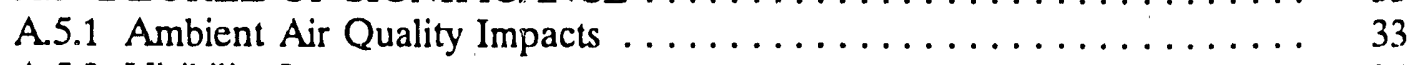

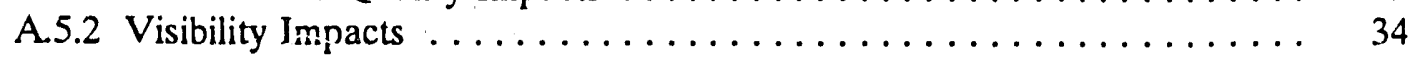

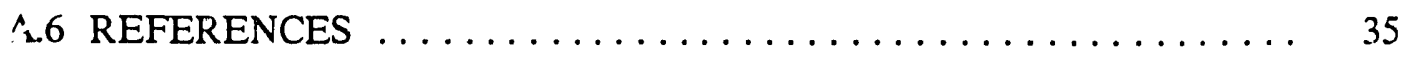




\section{LIST OF FIGURES}

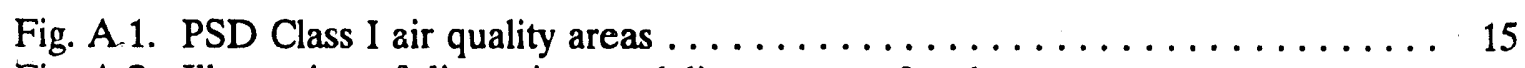

Fig. A.2. Illustration of dispersion modeling concept for the

Single Aircraft Instantaneous Line Source (SAILS) model . . . . . 23 


\section{LIST OF TABLES}

Table A.1. National Ambient Air Quality Standards (NAAQS) and Prevention of

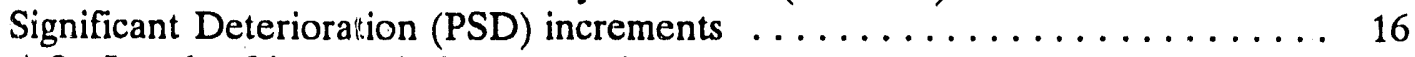

Table A.2. Levels of impact (LOI) categories for case study airspaces . . . . . . . . 27

Table A.3. Comparison of estimated low altitude flight emissions and national total emissions (in thousand tons per year) $\ldots \ldots \ldots \ldots \ldots \ldots \ldots \ldots \ldots \ldots \ldots$ 


\section{PREFACE}

This report was prepared by the Oak Ridge National Laboratory, P.O. Box 2008, Oak Ridge, TN 37831, under an Interagency Agreement (IAG) between the U.S. Department of Energy (DOE) and the Department of the Air Force (DOE IAG No. 1489-1489-A1, USAF No. F88-52), for the Air Force Engineering and Services Center (AFESC), Engineering and Services Laboratory, Tyndall Air Force Base, Florida.

This report summarizes work done between August 1988 and February 1990.

Captain W. P. Chepren and Captain M. T. Moss werc the AFESC/RDVS Project Officers. 


\title{
LIST OF ABBREVIATIONS AND ACRONYMS
}

\author{
AFESC Air Force Engineering Services Center \\ AFR Air Force Regulation \\ AQCR Air Quality Control Region \\ CAA Clean Air Act \\ CFR Code of Federal Regulations \\ DOE U.S. Department of Energy \\ EPA U.S. Environmerita! Protection Agency \\ GEIS Generic Environmental Impaci Statement \\ IAG Interagency Agreement \\ ISCST Industrial Source Complex Short-Term (model) \\ LOI level of impact \\ MAILS Multiple-Aircraft Instantaneous Line Source (model) \\ MOA Military Operations Area \\ MTR Military Training Roste \\ NAAQS National Ambient Air Quality Standards \\ NEPA National Environmental Policy Act \\ $\mathrm{NO}_{2} \quad$ aitrogen dioxide \\ $\mathrm{NO}_{\mathrm{x}} \quad$ nitrogen oxides \\ PM-10 particulate matter under 10 microns in diameter \\ PSD Prevention of Significant Deterioration (of air quality) \\ RA Restricted Area \\ SAC Strategic Air Command \\ SAILS Single-Aircraft Instantaneous Line Source (model) \\ $\mathrm{SO}_{2} \quad$ sulfur dioxide \\ TSP total suspended particulate (matter) \\ WC worst case
}




\section{EXECUTIVE SUMMARY}

This report describes the development and application of procedures to evaluate the potential impacts on air quality and visibility of low-altitude aircraft flights. The work summarized in this report was undertaken as part of the larger task of assessing the various potential environmental impacts associated with low-altitude military airspaces. The primary products of this larger task will be a Generic Environmental Impact Statement (GEIS) for Air Force Low-Altitude Flying Operations and an Environmental Impact Analysis Process (EIAP) Guide for Low-Altitude Airspace Proposals that will describe the recommended procedures for evaluating impacts in various categories (e.g. noise, wildlife, air quality, etc). The GEIS is bein $\tilde{\xi}$ prepared in accordance with the National Environmental Policy Act of 1969 (NEPA, Public Law 91-190) and Air Force Regulation (AFR) 19-2.

In accomplishing the air quality/visibility analysis objectives for the GEIS, the following tasks were completed

- development and application of an integrated air quality model and aircraft emissions database specifically for Military Training Route (MTR) or similar flight operations,

- selection and application of an existing air quality model to analyze the more widespread and less concentrated aircraft emissions from Military Operations Areas (MOAs) and Restricted Areas (RAs), and

- development and application of procedures to assess impacts of aircraft emissions on visibility.

Existing air quality models were considered to be inadequate for predicting groundlevel concentrations of pollutants emitted by aircraft along MTRs for two reasons: none of these models account for the intermittent and essentially instantaneous nature of the emissions, and/or none were practical because of their size, complexity, or input data requirements. Therefore, the Single-Aircraft Instantaneous Line Source (SAILS) model ?nd, later, the Multiple-Aircraft Instantaneous Line Source (MAII_S) model were developed to estimate potential impacts along MTRs or MTR-like airspace segments. An existing model, the U.S. Environmentil Protection Agency's ('EPA's) Industrial Source Complex Short-Term (ISCST) dispersion model, was chosen to estimate ground-level concentrations from the more widely distributed emissions occurring within MOAs and RAs. Finally, a protocol was developed and then applied in the field to determine the degree of visibility impairment caused by aircraft engine exhaust plumes.

The MAILS model was tested by comparing its results with those from a previously tested, FPA-approved dispersion model that had been configured to provide for a comparison of model performance. The comparison indicated very close agreement between the MAILS model and the EPA model for an MTR scenario. The existing model used for MOAs and RAs was not tested because it has been widely used and is based on generally accepted atmospheric dispersion principles. Testing was not applicable to the visibility impact assessment protocol.

The results of the aircraft emissions impact analysis were described in relation to objective criteria (see Appendix A) established to characterize the significance of the impacts. According to the objective criteria, the following results were obtained: 
- The ground-level air quality impacts of low-flying aircraft in MOAs and RAs are generally insignificant compared with all known air quality standards.

- The aesthetic impacts on visibility over national parks and wilderness areas are insignificant for exhaust plumes from all types of existing U.S. military aircraft.

- The ground-level air quality impacts of low-flying aircraft along MTRs or MTRlike airspace segments are potentiaily significant only with respect to the very stringent air quality standards applicable to certain national parks and wilderness areas, known as Prevention of Significant Deterioration (PSD) Class I areas.

Based on these findings, the key conclusion from this study is that air pollutant emissions from aircraft in low-altitude airspares are a potential concern only when the airspace overlies or is very near $[<1 \mathrm{~km}(<0.6$ mile)] a PSD Class I area. Also, the impacts, even over Class I areas, will generally be insignificant when the airspace flying operations are widely distributed (as is often the case in MOAs and RAs) as opposed to following a regularly prescribed route or path. Thus, environmental planning and assessment staff can focus the air quality analysis on only those airspaces that intersect PSD Class I areas.

For MTRs and MTR-like operations the MAILS model is a recommended tool for quickly and easily determining the potential significance of air quality impacts relative to PSD Class I standards. 


\begin{abstract}
This report describes the development and application of procedures to evaluate the effects of low-altitude aircraft flights on air quality and visibility. The work summarized in this report was undertaken as part of the larger task of assessing the various potential environmental imparts associated with low-altitude military airspaces. Accomplishing the air quality/visibility analysis for the GEIS included (1) development and application of an integrated air quality model and aircraft emissions database specifically for Military Training Route (MTR) or similar flight operations, (2) selection and application of an existing air quality model to analyze the more widespread and less concentrated aircraft emissions from Military Operations Areas (MOAs) and Restricted Areas (RAs), and (3) development and application of procedures to assess impacts of aircraft emissions on visibility.

Existing air quality models were considered to be inadequate for predicting groundlevel concentrations of pollutants emitted by aircraft along MTRs; therefore, the SingleAircraft Instantaneous Line Source (SAILS) and Multiple-Aircraft Instantaneous Line Source (MAILS) models were developed to estimate potential impacts along MTRs. Furthermore, a protocol was developed and then applied in the field to determine the degree of visibility impairment caused by aircraft engine exhaust plumes.
\end{abstract}




\section{INTRODUCTION}

\subsection{OBJECTIVE}

The objective of the tasks described in this report has been to evaluate the effects of emissions from low-altitude aircraft flights on air quality and visibility, inciuding the development and application of appropriate procedures.

\subsection{BACKGROUND}

The need to evaluate the air quality and visibility impacts of low-altitude airspaces is reinforced by the federally mandated environmental impact assessment process [required under the National Environmental Policy Act of 1969 (NEPA, Pub. L. 91-190) and Air Force Regulation (AFR) 19-2]. In accordance with NEPA, the U.S. Air Force has initiated the preparation of a Generic Environmental Impast Statement (GEIS) that addresses the generic environmental issues cornmon to low-level nying and will provide a basis for assessing the potential impacts of establishing now low-altitude military airspaces. The air quality and visibility analysis procedures desctibed in this report were developed in support of the GEIS and to facilitate future environmental znalyses.

Air quality regulations implemented pursuant to the Clean Air Act (CAA) and its amendments include National Ambient Air Quality Standards (NAAQS) (40 CFR Pt. 50) and Prevention of Significant Deterioratio. (PSD) regulations (40 CFR. Pt. 52), which limit the total and incremental concentrations, respectively, of certain air pollutants in the ambient air. The current NAAQS and PSD Class II and Class $I$ increments are shown in Table A.1 of Appendix A. PSD Class I increments apply in certain national parks and wilderness areas, while PSD Class II increments apply in most of the remainder of the country. The PSD Class I increments provide very stringent limitations on air quality degradation in Class I areas, where allowable incremental pollutant concentrations are generally an order of magnitude or more lower than in other areas.

The PSD regulations werc established pursuant to the CAA Amendments of 1977 (Pub. L. 95-95) to provide for more stringent control of emissions from major stationary pollutant sources. Low-flying aircraft are not subject to any of the analysis requirements established pursuant to the CAA and its amendments, including analysis of PSD increment consumption. However, to assess the potential air quality impacts as required by NEPA, measures established under the CAA (PSD incremenis and NAAQS) were applied to lowflying aircraft emissions to provide a yardstick with which to measure the significance of air quality impacts (see Appendix A).

Visibility protection for PSD Class I areas is mandated by the 1977 CAA amendments, in which Congress declared as a national goal the prevention of future visibility impairment and the remediation of existing visibility impairment in certain federally mandated Class I areas where such impairment results from man-made pollution (Section 169A of the CAA, 42 U.S.C. Sect. 7491). Quantitative, objective measures for determining such impairment were not defined in the CAA; however, visibility impairment includes reduction in visual range and atmospheric discoloration. 
In regulations implementing the 1977 CAA amendments, the U.S. Environmental Protection Agency (EPA) defined "adverse impact on visibility" as

... visibility impairment which interferes with the management, protection, preservation or enjoyment of the visitor's visual experience of the Federal Class I area. This determination must be made on a case-by-case basis taking into account the geographic extent, intensity, duration, frequency and time of visibility impairment, and how these factors correlate with (1) times of visitor use of the Federal Class I area, and (2) the frequency and timing of natural conditions that reduce visibility. (40 CFR Pt. 52.21)

The EPA has also interpreted visibility impairment to include effects visible within Class I areas and effects visible from within Class I areas (1979). In other words, any air pollution that degrades the scenic view of a person standing in a Clars I area is potential visibility impairment, even if the pollution is not directly over part of the Class I area. Thus, establishing a Military Training Route (MTR), Military Operations Area (MOA) or Restricted Area (RA) so that it simply skirts the edge of a Class I area does not in itself preclude visibility impairment froin aircraft exhaust plumes.

\subsection{SCOPE}

In accomplishing the air quality/visibility analysis objectives for the GEIS, the following tasks were completed:

- development and application of an integrated air quality model and aircraft emissions database specifically for MTR or similar flight operations,

- selection and application of an existing air quality model to analyze the more widespread and less concentrated aircraft emissions from MOAs and RAs, and

- development and application of procedures to assess impacts of aircraft emissions on visibility.

Existing air quality models were considered inadequate for estimating ground-level concentrations of pollutants emitted by aircraft along MTRs because these models did not account for the intermittent and essentially instantaneous nature of the emissions and/or because their size, complexity, and input data requirements made them impractical. Therefore, the Multiple-Aircraft Instantaneous Line Source (MAYLS) model (Liebsch 1990) was developed to estimate impacts along MTRs or MTR-like airspace segments. An existing model, EPA's Industrial Source Complex Short-Te!m (ISCST) dispersion model (EPA 1987), was chosen to estimate ground-level concentrations from the more widely distributed emissions occurring within MOAs and RAs. Finally, a protocol was developed and then applied in the field to determine the degree of visibility impairment by aircraft engine exhaust plumes. 


\section{METHODS SELECTION AND DEVELOPMENT}

This section summarizes the process of selecting and developing the methods used to evaluate potential air quality and visibility impacts from low-altitude flying operations. A more detailed discussion of this process is found in Appendix A and in the MAILS user's guide (Liebsch 1990).

\section{AIR QUALTTY MODELS}

\subsection{Militar Training Routes}

Aircrait emissions along MTRs can best be characterized as a collecion of instantaneous line sources. Research into the availability and applicability of existing instantaneous line source models yielded only one such candidatc, the FSCBG-2 code developed for the U.S. Forest Service and the U.S. Army by the H. E. Cramer Co., Salt Lake City, Utah. The FSCBG-2 model FORTRAN computer code and user's guide (Bjorklund, Bowman, ano Dodd undated) were obtained from the $\mathrm{H}$. E. Cramer Co. and reviewed to determine potential applicability to the dispersion of aircraft emissions along MTRs. While the FSCBG-2 model appears to be a state-of-the-art modeling technique ior this type of source, the decision was made not to use it for the GEIS because of the need to make a large number of model runs for different aircraft types, flight altitudes, and meteorological conditions. Given the run time, amount of input data required, and complexity of making a single FSCBG-2 run, this model was determined to be impractical for auch analysis. Also, for future impact assessment it is desirable to have a relatively simple, user-friendly model that would allow rapid turnaround in the route planning and development process. Therefore, a simple "screening" model, which was named the Single- Aircraft Instantaneous Line Source (SAILS) model, was developed to complete the required analysis for the GEIS. An air quality screening model is generally defined as one that provides conservative concentration estimates and can be run quickly with a minimum of user input. If warranted by the results of screening, a more detailed model could be run (i.e. the screening model results determine the need for a more detailed analysis).

The SAILS dispersion model was used to assess the potential air quality impacts of MTRs for the GEIS. This assessment is described in Appendix A of this report and will be included in the GEIS. The SAILS model was later modified by integrating an aircraft emissions database and adding the capability for multiple aircraft assessment in a single model run. The modified model was named MAILS (Liebsch 1990).

\subsection{Military Operations and Restricted Areas}

Because most flight operations in MOAs and RAs do not follow prescribed routes, a decision was made to model these emissions as "area sources." The EPA IiCST (EPA 1987) dispersion model was selected for this application because it is a widely used, EPA-approved model that is capable of simulating impacts from area source einissions. 


\section{VISIBILTY ASSESSMENT PROCEDURES}

Visibility impacts from low-level training flights are expected to be restricted to possible plume blight (a visible plume traceable to a specific source) and should not include regional-scale effects such as haze or visual range reduction (see Appendix A). The extent, intensity, frequency, and duration of any plume blight effects can best be determined and cocumented by human observation and photographing of plumes from military aircraft under a variety of environmental conditions. To bound the maximum potential visibility impacts, it was not necessary to observe and photograph all military aircraft. Instead, a worst case (WC) aircraft was selected for observation on the basis of estimated emissions of particulate matter (soot) and nitrogen oxides $\left(\mathrm{NO}_{x}\right)\left(\mathrm{NO}_{2}\right.$ is a visible gas). Basec' on these criteria, the B-52 aircraft was chosen for observation of visible emissions. 


\section{METHODS APPLICATION AND RESULTS}

This section summarizes the application of procedures to evaluate air quality and visibility impacts of low-altitude flying operations, and the results obtained from the analysis. A more detailed discussion of the analysis methodology and results is provided in Appendix A.

\subsection{AIR QUALITY}

\subsubsection{Military Training Routes}

The SAILS model (see Appendix A) was arplied to several case study MTRs as part of the air quality analysis conducted for the LEIS. The additive effects of multiple aircraft passe: during the averaging periods of interest were accounted for by marlual calculation, based on the results of a single SAILS run for each aircraft at each altitude of concern. As previously stated, the MAILS model was developed later to allow assessment of multiple aircraft passes in a single run and to incorporate an integrated emissions database for easy interactive access to aircraft emissions data.

'The results of the GEIS air quality analysis for MTRs are described in detail in Appendix A. The key findings from this analysis are as follows:

- the potential air quality impacts of MTRs are generally insignificant (less than five percent of standards) with respect to the NAAQS and PSD Class II increments, and

- the air quality impacts of MTRs are potentially significant (possibly over five percent of standards) if the MTRs pass over or adjacent to PSD Class I areas (certain national parks and wilderness areas).

\subsubsection{Military Operations and Restricted Areas}

The air quality impacts of MOAs and RAs were modeled as area sources using the ISCST model (EPA 1987). This analysis is described in detail in Appendix A. While typical MOA and RA operations are expected to occur over a widely dispersed portion of these areas, it is important to consider as a special case any operations in these areas that routinely use a prescribed route such as with MTRs. If such operations occur within an MOA, RA, or other airspace, the appropriate modeling tool would be the MAILS model rather than an area source model such as ISCST.

The results of the case study analysis for the GEIS indicate that the potential air quality impacts from MOAs and RAs (when operations are not concentrated along a particular path) are insignificant with respect to all NAAQS and PSD Class II and Class I increments. Thus, the only cases in which future MOAs, RAs, or similar areas need to be modeled are those in which the flight operations are concentrated along prescribed paths or routes that pass over or near a PSD Class I area. 


\subsection{VISIBILITY}

Plume observations and photographs were obtained for a B-52 during a radar siting exercise in north-central South Dakota during early May 1989. The photographs were taken in the late morning hours against a nearly cloudless blue sky, thus providing a good background against which the dark plumes could be contrasted. The exercise involved low-altitude maneuvers similar to those that occur along MTRs. A programmable clock on the 35-mm camera was used to imprint on each frame the time of the photo to the nearest second. Sequential photographs at 3-5 s intervals were taken of a fixed field of view during and after aircraft passage, until the plume was no longer visible to the observer.

Visual inspection of nine separate photo sequences indicated that the times required for the exhaust plumes to become invisible ranged from 4-19 $\mathrm{s}$ after aircraft passage. Based on these results, the visibility impacts of B-52 exhaust plumes were judged to be insignificant, because the visible plumes are relatively short-lived and are not much more of a visible intrusion than the aircraft itself. Also, the short dissipation times imply that it is primarily the initially dominant aircraft wake turbulence which is responsible for the rate of dissipation, rather than normal atmospheric turbulence. This supports a conclusion that observed dissipation times would not vary significantly under various atmospheric turbulence conditions.

Because B-52 flights are consilered the WC scenario in terms of visibility impacts, it was concluded that all types of military aircraft now in use would have insignificant impacts on visibility in PSD Class I areas. Furthermore, because newer aircraft engines are generally more efficient and cleaner burning, and because most new engines are subject to smoke emission standards (40 CFR Pt. 87), it is expected that as older aircraft such as the B-52 are eventually phased out, visible smoke plumes will become even less noticeable. 


\section{CONCLUSIONS}

Methods for the assessment of air quality and visibility impacts from low-flying aircraft emissions were developed and applied to selected military airspaces and aircraft. It was determined that impairment of visibility was insignificant for all types of existing U.S. military aircraft. Predicted ground-level air pollutant concentrations from all types of military airspaces were found to be negligible with respect to all NAAQS and PSD Class II increments. Ground-level air pollutant concentrations caused by low-altitude MTRs or MTR-like operations are potentially significant (possibly over five percent of standards) only with respect to PSD Class I increments, which apply primarily to certain nation:l parks and wilderness areas. Therefore, future air quality analyses conducted in response to NEPA or other environmental analysis requirements need only address those airspaces for which MTR or MTR-like operations would occur over or near [within $-1 \mathrm{~km}$ $(\sim 0.6$ mile) of] PSD Class I areas.

The MAILS model has been developed specifically for estimating ground-level concentrations from low-altitude MTR or MTR-like operations. The MAILS model is the recommended tool for analyzing the air quality impacts of such operations on PSD Class I areas. 


\section{REFERENCES}

Bjorklund, J. R., Bowman, C. R., and Dodd, G. C. (undated). User Guide-Forest Service Aerial Spray Computer Model-FSCBG-2 (Review Draft), FPM 88-5. USDA Forest Service, Forest Pest Management, Davis, Calif.

EPA (U.S. Environmental Protection Agency) 1979. Protecting Visibility: An EPA Report to Congress, EPA-450/5-79-008, EPA, Research Triangle Park, N.C.

EPA (U.S. Environmental Protection Agency) 1987. Industrial Source Complex (ISC) Dispersion Model User's Guide-Second Edition (Revised), EPA-450/4-88-002, EPA, Research Triangle Park, N.C.

Liebsch, E. J. 1990. Multiple-Aircraft Instantaneous Line Source (MAILS) Dispersion Model User's Guide, ESL-TR-89-59, Air Force Engineering and Services Center, Tyndall Air Force Base, Fla. 
APPENDIX A

ASSESSMENT OF ENVIRONMENTAL IMPACTS OF LOW ALTITUDE FLYING OPERATIONS ON AIR QUALTTY

1112 


\section{A.1 INTRODUCTION: FRAMING OF THE ISSUES}

\section{A.1.1 Issues Raised in Scoping Process}

Compared with other issues raised in the public scoping process for the Generic Environmental Impact Statement (GEIS) for Air Force Low Altitude Flying Operations, air quality received relatively little attention. With regard to air quality, only a few questions or concerns were raised. These concerns were generally related to the types and quantities of emissions from the aircraft and whether these emissions are harmful to either humans or livestock. This appendix assesses the potential impacts to air quality of Air Force low altitude flying operations.

\section{A.1.2 Regulatory Issues}

There are two aspects of air quality potentially affected by low altitude flying operations. One aspect concerns the concentrations of various regulated air pollutants which could be increased by emissions from the aircraft engines. National Ambient Air Quality Standards (NAAQS) have been established in order to prevent adverse impacts on public health and welfare as a result of air pollution. In addition, Prevention of Significant Deterioration (PSD) regulations have been promulgated-pursuant to the Clean Air Act (CAA) amendments of 1977-in order to keep air quality from deteriorating significantly in areas that already meet the NAAQS. The PSD regulations established strict emissions controls and certain allowable pollutant concentration increments which are more stringent than the NAAQS (see Table A.2). These PSD requirements apply only to major stationary sources, thus excluding mobile sources such as low-flying aircraft. However, in order to satisfy the air quality impact analysis requirements of the National Environmental Policy Act (NEPA) (Pub. L. 91-190), measures established under the CAA (NAAQS and PSD increments) were applied to low-flying aircraft emissions to provide a yardstick by which to measure and evaluate the significance of air quality impacts.

$A$ second aspect of air quality which might be affected by low altitude flying operations is that of visibility. Visibility protection is mandated by the CAA, Section 169A, for certain parks and wilderness areas which were designated as PSD Class I areas in order to attain and maintain pristine air quality in these areas. The 1977 CAA amendments designated as Class I all of the following areas that were in existence on August 7, 1977:

(1) international parks;

(2) national wilderness areas exceeding 5,000 acres;

(3) national memorial parks exceeding 5,000 acres; and

(4) national parks exceeding 6,000 acres 
The above criteria resulted in the designation of 156 parks and wilderness areas as PSD Class I areas (Fig. A.1). Visibility protection is required only for those Class I areas where the Federal Land Masiagers (FLMs) of the areas have determined visibility to be an important value. The FLMs determined that visibility was an important value in 154 of the 156 Clas: I areas defined pursuant to the $1977 \mathrm{CAA}$ amendments. The 154 visibility protection $\mathrm{a}_{4}$ eas are listed in 40 CFR Pt. 81.401-81.436 and include all the areas shown in Fig. A.1, except for the Rainbow Lake (Wisconsin) and Bradwell Bay (Florida) Wilderness Areas.

\section{A.1.21 Ambient air quality and PSD}

The CAA, as amended in 1970, required the establishment of NAAQS for the protection of public health and welfare. It delegated to the U.S. Environmental Protection Agency (EPA) the responsibility for establishing these standards and for promulgating regulations to attain and maintain NAAQS. The CAA amendments of 1977 established PSD requirements in order to maintain pristine air quality in certain parks and wilderness areas (Class I areas) and to maintain good air quality in other areas of the country (Class II areas) that were already in compliance with NAAQS. Toward these ends, the 1977 CAA amendments established PSD Class I and Class II concentration increments, which limited the amounts of additional pollution that could be added to the atmosphere, thus establishing more stringent limitations than required by the NAAQS in many areas of the country. To date, the EPA has established PSD increments for sulfur dioxide $\left(\mathrm{SO}_{2}\right)$, total suspended particulate matter (TSP), and nitrogen dioxide $\left(\mathrm{NO}_{2}\right)$. An absolute limit to the allowable pollution levels is still provided by the NAAQS, which are not to be exceeded, regardless of allowable PSD Class II or Class I concentration increments.

The current NAAQS (40 CFR Pt. 50) and PSD Class II and Class I increments (40 CFR Pt. 52.21) are shown in Table A.1. Note that the Class I increments allow for very little additional pollution in the parks and wilderness areas designated by the CAA. For $\mathrm{SO}_{2}$ and $\mathrm{NO}_{2}$, the Class I increments are at least an order of magnitude lower than the NAAQS or the PSD Class II increments. The NAAQS and PSD increments apply to pollutant concentrations in air at ground-level.

\section{A.1.22 Visibility}

With the 1977 CAA amendments, Congress declared as a national goal the prevention of future and the remedying of existing visibility impairment in certain federally mandated Class I areas, where such impairment results from man-made pollution (Section 169A of the CAA, 42 U.S.C. Sect. 7491). Quantitative, objective measures for determining such impairment were not defined in the CAA; however, it was specified that visibility impairment included reduction in visual range as well as atmospheric discoloration. 
15

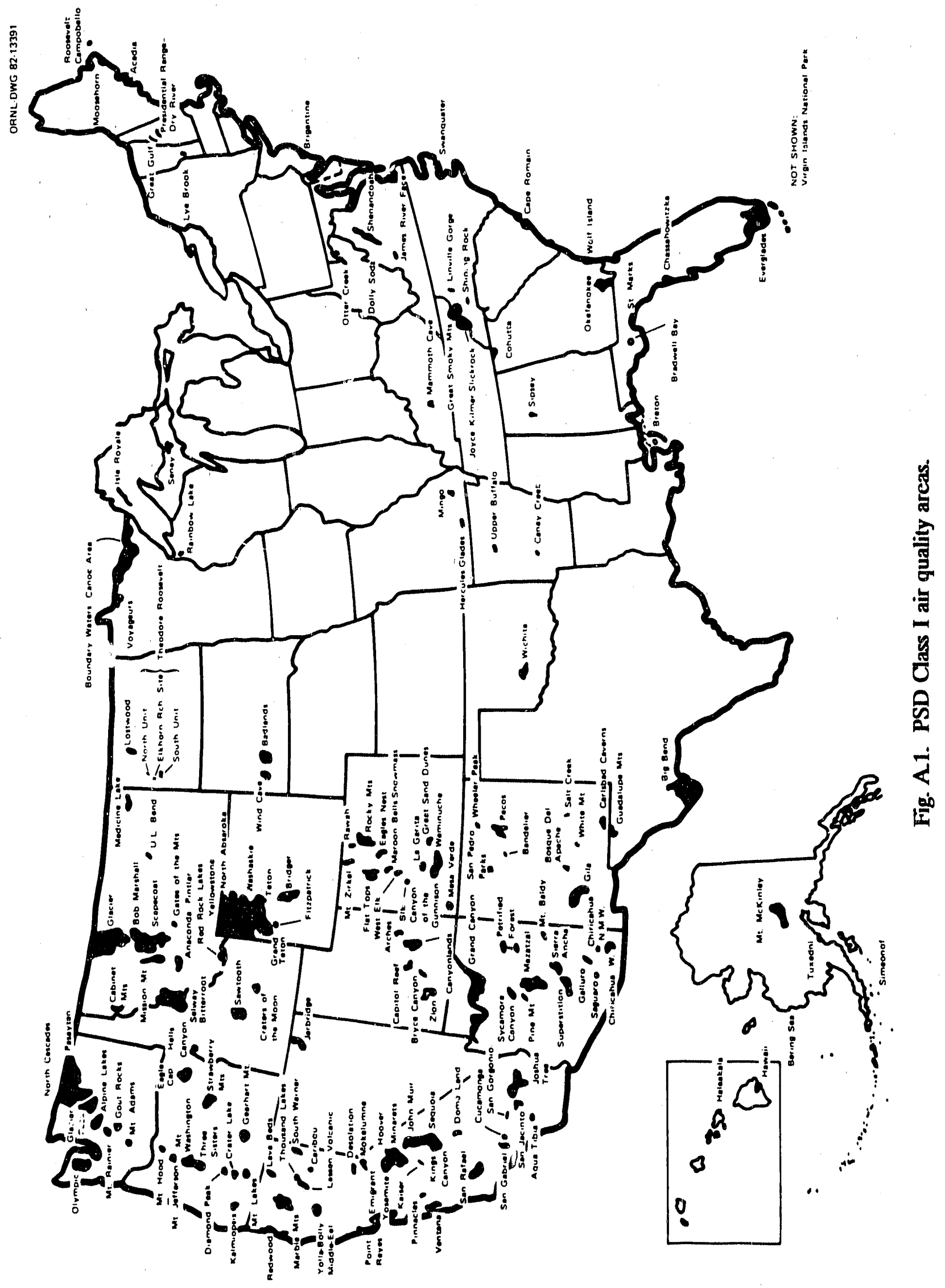


Table A.1. National Ambient Air Quality Standards (NAAQS) and Prevention of Significant Deterioration (PSD) increments"

\begin{tabular}{|c|c|c|c|c|}
\hline \multirow{3}{*}{$\begin{array}{l}\text { Pollutant } \\
\begin{array}{l}\text { Nitrogen } \\
\text { dioxide }\end{array}\end{array}$} & \multirow{3}{*}{$\begin{array}{c}\begin{array}{c}\text { Averaging } \\
\text { time }\end{array} \\
\text { Annual }\end{array}$} & \multirow{3}{*}{$\begin{array}{r}\text { NAAQS } \\
100\end{array}$} & \multicolumn{2}{|c|}{ PSD Increments } \\
\hline & & & Class II & Class I \\
\hline & & & 25 & 2.5 \\
\hline $\begin{array}{l}\text { Sulfur } \\
\text { dioxide }\end{array}$ & $\begin{array}{l}\text { 3-hr } \\
\text { 24-hr } \\
\text { Annual }\end{array}$ & $\begin{array}{r}1,300^{b} \\
365^{b} \\
80\end{array}$ & $\begin{array}{r}512^{b} \\
91^{b} \\
20\end{array}$ & $\begin{array}{r}25^{b} \\
5^{b} \\
2\end{array}$ \\
\hline $\begin{array}{l}\text { Particulate } \\
\text { matter }\end{array}$ & $\begin{array}{l}24-\mathrm{hr} \\
\text { Annual }\end{array}$ & $\begin{array}{r}150^{b, c} \\
50^{c}\end{array}$ & $\begin{array}{r}37^{b, d} \\
19^{d}\end{array}$ & $\begin{array}{r}10^{b, d} \\
5^{d}\end{array}$ \\
\hline $\begin{array}{l}\text { Carbon } \\
\text { monoxide }\end{array}$ & $\begin{array}{l}1-\mathrm{hr} \\
8-\mathrm{hr}\end{array}$ & $\begin{array}{l}40,000^{b} \\
10,000^{b}\end{array}$ & -. & - \\
\hline Ozone & $1-\mathrm{hr}$ & $235^{c}$ & -- & -- \\
\hline lead & $\begin{array}{r}\text { Calendar } \\
\text { quarter }\end{array}$ & 1.5 & -- & $\therefore$ \\
\hline
\end{tabular}

"All concentrations are in units of micrograms/cubic meter.

b iot to be exceeded more than once per year.

'Particulate matter under 10 microns in diameter.

'Total suspended particulate matter (TSP).

Not to be exceeded on more than one day per year.

In its regulations implementing the $1977 \mathrm{CAA}$ amendments, the EPA defined "adverse impact on visibility" as

... visibility impairment which interferes with the management, protection, preservation or enjoyment of the visitor's visual experience of the Federal Class I area. This determination must be made on a case-by case basis taking into account the geographic extent, intensity, duration, frequency and time of visibility impairment, and how these factors correlate with (1) times of visitor use of the Federal Class I area, and (2) the frequency and timing of natural conditions that reduce visibility (40 CFR Pt. 52.21).

The EPA has also interpreted visibility impairment to include effects visible within Class I areas and effects visible from within Class I areas (1979). Thus, establishing a low altitude training area so that it simply skirts the edge of a Class I area does not in itself preclude visibility impairment from visible exhaust plumes. 


\section{A.2 LITERATURE REVIEW}

\section{A.2.1 Ambient Air Quality Impact Assessment}

Addressing the impact of low-flying aircraft on ambient air quality requires the selection or development of methods or models for estimating the impacts. Also required are pollutant emissions data for aircraft engines, data on existing or background air pollutant concentrations, and data describing the aircraft type, flight frequency, and orientation with respect to a ground-level receptor.

For most types of pollutant sources, the estimation of impacts is typically accomplished with the use of atmospheric dispersion models. Dispersion models have heen developed and distributed for use in ambient air quality impact assessment (EPA 1986). These models are generally applicable to the more common types of pollutant sources such as power plant stacks (continuous elevated point sources), surface coal mines (continuous area sources), and highways (continuous line sources). The assessment of air quality impacts from low flying aircraft requires the simulation of an essentially instantaneous elevated line source, which is a type for which relatively few field or theoretical dispersion studies hive leen conducted.

Miller (1980) has constructed a mathematical model for calculating the dispersion and resulting deposition distribution of pesticides released from crop-dusting aircraft. This model was applied to the release of pesticides in droplet form at a very low altitude [approximately $3 \mathrm{~m}(10 \mathrm{ft})$ ]. However, this type of droplet deposition model is not applicable to the type of pollutant emissions expected from aircraft engines, which will primarily be in the form of gases and very fine particles.

Slade (1968, pp. 170-73) describes two field studies conducted in the early 1960s which investigated the dispersion and resulting downwind concentrations of tracers released from aircraft. Both studies were set up so that the line of tracer release was perpendicular to the wind direction. The worst case (WC) impacts, however, would result when the line of release is parallel to the wind direction, because this results in a continuous exposure to plume material at a fixed ground-level location (receptor). Winds perpendicular to the line of emissions would result in only a brief period of exposure at any receptor, resulting in lower concentrations for the averaging times of concern (1 hr and longer). One conclusion of these studies, based on the measured ambient turbulence data, was that vertical diffusion rates were higher than would be expected. This effect was attributed to the initial enhancement of turbulence and diffusion caused by the passage of the releasing aircraft.

The U.S. Forest Service (Dumbauld, Bjorklund and Saterlie 1980) and later the U.S. Army (Bjorklund, Bowman, and Dodd undated; Geary 1988) have funded the development of a model which is capable of simulating the surface deposition and concentration of gases or acrosols released from aircraft. The latest version of this Fortran computer code, known as the FSCBG-2 model, would seem to represent the state of the art for the estimation of ground-level pollutant impacts resulting from low altitude aircraft flights along military training routes (MTRs) or other relatively narrow flight corridors. The FSCBG-2 model is capable of accounting for the additional dispersion of effluent caused by the turbulent wake of the aircraft, based on the particular aircraft characteristics. One limitation of the FSCBG-2 model for low altitude flight impact assessment is that it simulates the impact from only a single, linear flight path. This limitation could be overcome for impact assessment purposes by simply making multiple 
model runs and summing the conceistrations at each receptor in order to evaluate the effects of multiple aircraft training missions or repeaied flights within the averaging period of interest.

For estimating impacts over military operations areas (MOAs) and restricted areas (RAs), it is probably best to use area sources to simulate emissions from the more widespread and variable flight paths. A model such as the Industrial Source Complex Short-Term (ISCST) dispersion model (EPA 1987) is an appropriate tool for estimating impacts from area sources.

For aircraft emissions, the EPA provides emissions factors for carbon monoxide (CO), nitrogen oxides $\left(\mathrm{NO}_{\mathrm{x}}\right)$, hydrocarbons $(\mathrm{HC}), \mathrm{SO}_{2}$, and TSP for a number of commercial and military aircraft engines (1985). Seitchek (1985) provides a more comprehensive listing of emission factors for most aircraft engines in the U.S. Air Force inventory. Although the Seitchek report does not provide emission factors for all Air Force aircraft engines, when supplemented with emissions data from the EPA (1985) and fuel sulfur data (Shelton 1976), the emissions database is sufficient for impact assessment of most Air Force aircraft. For scenarios involving a mixture of Air Force and Navy aircraft, the above data sources can be supplemented with a computerized emissions database recently developed for the Naval Air Propulsion Center by Northern Research and Engineering Corporation (Platt et al. 1988).

\section{A.2.2 Visibility Impact Assessment}

According to the CAA, Section $169 \mathrm{~A}$, impairment of visibility in Class I areas (primarily national parks and wilderness areas above a specified size) by any existing or future man-made air pollution sources is to be remedied or prevented. Impairment of visibility was defined by the CAA to mean (1) reduction in visual range and (2) atmospheric discoloration.

Reduction in visual range is typically caused by an accumulation of pollutants on a regional scale. Emissions studies (Lorang 1978) have indicated that the man-made pollutants emitted by commercial aircraft at or in the vicinity of airports is generally less than $1 \%$ of the total made-made emissions in any Air Quality Control Region (AQCR), which is typically a sub-state sized area. Military aircraft emissions in most AQCRs are probably less than emissions from commercial aircraft because of the much higher volumes of commercial traffic in most areas, suggesting that military aircraft emissions do not contribute significantly to regional-scale pollution and haze.

The EPA (1979) has interpreted atmospheric discoloration to include plume blight effects as well as effects attributable to large conglomerations of sources, which might produce, for example, an urban plume. Plume blight refers to a traceable plume of visible effluent emanating from a specific pollution source. In assessing the potential for adverse visibility impacts by low altitude training flights, it is apparent that plume blight is the only important concern.

Modeling techniques have been developed for the prediction of visibility impacts based on source emissions and other data (EPA 1980). However, these techniques were developed for application to large, continuous, stationary point sources of pollution, such as coal-fired power plants.

Williams, Treiman, and Wecksung (1979) have developed a simulated photographic technique to predict the effects of incremental changes in source emissions and various environmental parameters. This technique requires that a baseline plume photograph be taken under carefully measured environmental conditions. A computer model is then used 
along with high-resolution color graphics output to produce a "picture" of the landscape/sky under varying emissions and environmental conditions. The authors point out that the perceptibility of a plume is dependent on the viewing angle relative to the sun, the background (clouds, sky, terrain) against which the plume is viewed, plumeobserver geometry, the amount of background regional haze, the atmospheric stability, relative humidity, and perhaps other environmental parameters. They also stated that actual plume photographs are probably the most accurate method of documenting visibility impacts.

\section{A.2.3 Findings}

\section{A.23.1 Ambient air quality and PSD}

The recently developed FSCBG-2 dispersion model (H. Geary, H. E. Cramer Company, Inc., Salt Lake City, personal communication to E. J. Liebsch, Oak Ridge National Laboratory, Oak Ridge, Tenn., Jan. 28, 1988) is probably the most sophisticated tool for assessing ambient air quality impacts of pollutant emissions from low-flying aircraft along MTRs. This model can be applied to the situation of instantaneous, elevated, linesource emissions, which is essentially simulated by an aircraft flying a straight path. However, because of the size, complexity, and run time of the FSCBG-2 model, a simpler screening model was developed by Oak Ridge National Laboratory (ORNL) for application to low-flying aircraft. The ORNL model, dubbed the SAILS (single aircraft instantaneous line source) model, takes less than a minute to run on an IBM-compatible personal computer. The SAILS model also requires much simpler input than the FSCBG2 model and was designed specifically for the WC scenario, in which the flight path is parallel to the wind direction.

In general, emissions from low-flying aircraft over MOAs and RAs tend to occur in a more scattered, dispersed pattern than emissions associated with MTRs. Thus, the EPA ISCST dispersion model, which is capable of handling area source emissions, is appropriate for estimating impacts from MOAs and RAs.

\section{A.23.2 Visibility}

Visibility impacts from low altitude training flights are expected to be restricted to possible plume blight effects rather than regional-scale effects such as haze or visual range reduction. The extent, intensity, frequency, and duration of any plume blight effects can best be determined and documented by human observation and plume photography from military aircraft under a variety of environmental conditions. For the purpose of bounding the range of potential visibility impacts, it is probably not necessary to observe and photograph all military aircraft but rather a set of aircraft selected on the basis of their estimated emissions of $\mathrm{NO}_{x}\left(\mathrm{NO}_{2}\right.$ is a visible gas) and particulate matter.

\section{A.3 GEIS RESEARCH}

\section{A.3.1 Methodology}

\section{A.3.1.1 Ambient air quality impact assessment}

The assessment of ambient air quality impacts for the selected case study airspaces required (1) aircraft engine ernissions data, (2) data desirribing the dimensions and 
locations of the selected airspaces, (3) background or existing air quality data for the geographic areas underlying the airspaces, and (4) the choice of an atmospheric dispersion model or models for predicting ground-level concentrations of emitted pollutants.

\section{Aircraft engine emissions data}

The aircraft engine emissions data were primarily drawn from Seitchek (1985) but were supplemented with data from other snurces (EPA 1985; Shelton 1976; Platt et al. 1988). The $\mathrm{SO}_{2}$ emissions rates for all aircraft engines were calculated based on a fuel sulfur content of $0.05 \%$, which is on the high end of the numerous aviation fuel test results reported by Shelton (1976). The aircraft engine emissions data were multiplied by the number of engines for each aircraft type to generate total emission rates for each aircraft, which were then entered into a file associated with the ORNL airspace database. The dispersion modeling analysis utilized emissions data for an "intermediate" engine operating mode as represented in Seitchek (1985). However, data from other sources were not generally categorized using the same terminology as the Seitchek report. For these other sources, a data point was chosen which most closely corresponded to approximately $75 \%$ of the maximum throttle or fuel flow rate under normal engine operating conditions, apart from aft-rburner or other special modes not intended for continuous operation.

The pollutant types modeled for the case studies were $\mathrm{SO}_{2}, \mathrm{NO}_{2}$, particulate matter under 10 microns in diarneter (PM-10), TSP, and CO. PM-10 emissions were conservatively assumed to be equal to the calculated TSP emissions. Estimation of both TSP and PM-10 impacts was necessary since the NAAQS are now set :vith respect to PM-10, while PSD increments are still set with respect to TSP. EPA will eventually promulgate PSD increments for PM-10. NO emissions were conservatively assumed to be $100 \%$ in the form of $\mathrm{NO}_{2}$ for the dispersion modeling analysis.

For MTTis, an important variable in determining the relative importance of groundlevel impacts is the mass of pollutant emitted per unit length of route. Each MTR in the case study group was inspected using the Area Planning AP/1B Charts (Defense Mapping Agency 1988) to determine if and where other MTR segments were concurrent with part of the case study route. Each case study route was divided into segments, with each segment representing a unique collection of concurrent routes. On the Strategic Air Command (SAC) rJute IR-474, for example, as many as eight concurrent routes existed along a particular segment, while along other segments, IR-474 was the only established route. For each unique route segment, the total aircraft emissions per unit length of route were determined using the airspace database. Thus, the analysis of air quality impacts from concurrent route segments satisfies the NEPA requirement to evaluate the cumulative impacts of similar actions (40 CFR Pt. 1508.25).

For MOAs and RAs, the flight paths are generally more widely scattered both horizontally and vertically. Therefore, emissions for all aircraft types using a particular case study MOA or RA were combined and modeled as a single source for the purpose of air quality impact assessment. The total annual emissions for each case study MOA and RA were obtained by summing the results of the following multiplication for each aircraft type:

Emission rate $(\mathrm{lb} / \mathrm{hr}) \times$ Flight duration $(\mathrm{hr}) \times$ Annual number of flights 
The flight duration for the case study MOAs and RAs was assumed to be $0.5 \mathrm{hr}$, except for the Yukon $1 \& 2 \mathrm{MOA}$, for which a 1-hr flight duration was assumed. These approximations were based on discussions with the scheduling commands for these airspaces.

Airspace dimensions anū locations

The lengths of MTRs and the areas of MOAs and RAs were obtained from the Airspace Database. These dimensions were used to compute emissions per unit area for the MOAs and RAs and emissions per unit length for MTRs.

AP/1B Area Planning Charts and VFR/IFR Wall Planning Charts were used to locate the case study airspaces with respect to geographic features. Each case study airspace was compared with areas of critical air quality concern, namely PSD Class I areas (Fig. A.1) and NAAQS non-attainment areas.

Existing air quality data

Because of the great expanse of areas covered or crossed by the case study. airspaces, no attempt was made to gather monitored pollutant data under each of the low altitude flight airspaces. Rather, the EPA was contacted to obtain a listing of the most recent NAAQS non-attainment status, by county, for the entire United States.

\section{Choice of air quality models}

Aircraft emissions along MTRs can best be characterized as a collection of instantaneous line sources. Research into the availability and applicability of existing instantaneous line source models yielded only one such candidate, that being the FSCBG-2 code, developed for the U.S. Forest Service and the U.S. Army by the H. E. Cramer Co. (H. Geary, H. E. Cramer Company, Inc., Salt Lake City, personal communication to E. J. Liebsch, Oak Ridge National Laboratory, Oak Ridge, Tenn., Jan. 28, 1988). The FSCBG-2 model Fortran computer code and user's guide (Bjorklund, Bowman, and Dodd undated) were obtained from the H. E. Cramer Co. and reviewed to determine the potential applicability of this model to the dispersion of aircraft emissions along MTRs. While the FSCBG-2 model appeared to be the state-of-the-art modeling technique for this type of source, the decision was made not to use it for the GEIS because of the need to make a large number of model runs for different aircraft types, altitudes, and meteorological conditions. Given the run time, amount of input data required, and complexity of making a single FSCBG-2 run, this model was determined to be impractical for this analysis. Therefore, ORNL developer a simple screening model, the Single Aircraft Instantareous Line Source (SAILS) model, to complete the required analysis in a timely fashion.

The SAILS model calculates what are considerea to be WC 1-hr concentrations for a single linear flight path, which is assumed to be parallel to the wind direction. For a crosswind situation, a ground-level receptor would be impacted for only a brief period, resulting in much lower 1 -hr concentrations than for the paraliel wind case.

SAILS calculates the concentrations for an array of wind speed;atmospheric stability combinations vith a single run. These combinations are identical to those used in the EPA PTPLU model (EPA 1982), which is an EPA-approved screening model for single continuous point sources. The dispersion coefficients used in the SAILS model are identical to those used by the EPA ISCST dispersion model (EPA 1987) when applied to 
point source plumes without downwash-induced dispersion enhancement. The SAILS model assumes wind speed and direction to be constant in space and time.

The SAILS model divides the aircraft exhaust plume, which is essentially an instantaneous line source, into puffs, each having a pollutant mass equal to the emissions contained in a $100-\mathrm{m}$ (328-ft) segment of flight path. This dispersion modeling concept is illustrated in Fig. A.2. Concentrations are computed for each wind speed/stability combination at a ground-level, plume centerline location by summing the contributions of all puffs which pass the location in a 1-hr period. The contributions to total exposure from puffs more than $1 \mathrm{hr}$ of travel time away are expected to be small for most meteorological conditions and were not considered in ubtaining maxiinum concentration estimates for periods longer than $1 \mathrm{hr}$. Furthermore, because low altituite wind directions are unlikely to remain constant for longer than 1-hr, the same receptor would probably not be exposed to impacts from the centerline of the puffs/plume for longer periods.

The only input data required to run the SAILS model are (1) the release height (aircraft altitude) above ground-level (meters), (2) the surface inversion or mixing height (meters), (3) the aircraft pollutant emission rate (g/s), and (4) the aircraft airspeed (miles/hr). Listings of the SAILS model Fortran computer code and a sample of SAILS output are provided in Attachment 1.

As explained earlier, each case study MTR was divided into segments, with each segment consisting of a unique set of concurrent routes. For each route the airspace database contained the monthly number of scheduled sorties by aircraft type. These data and the aircraft pollutant emissions data were used to compute the emissions density per unit length. In most cases it was obvious which route segment would have the greatest potential ground-level impacts because most of the routes had a consistent minimum altitude. In a case where a route segment did not have the highest emissions density but had a lower minimum altitude than the segment with the highest emissions density, it was necessary to model more than one route segment to determine which one produced the highest ground-ievel impact. Any route segmen' passing over or near a Class I area was also modeled to compare the predicted WC impacts with the stringent Class I allowable pollutant increments. For all route segments with a minimum altitude of ground-level, a minimum release height of $200 \mathrm{ft}(61 \mathrm{~m})$ was used as model input, since it would be only rarely that aircraft would fly lower than this altitude along MTRs. Typically, aircraft flying MTRs stay at least $400 \mathrm{ft}(122 \mathrm{~m})$ above ground.

In order to compare maximum predicted impacts from MTRs with NAAQS and PSD increments, it was necessary to calculate concentrations for averaging periods of $1 \mathrm{hr}$, $3 \mathrm{hr}, 8 \mathrm{hr}, 24 \mathrm{hr}$, and 1 year (see Table A.1). The following assumptions were used in calculating maximum concentrations for each averaging period:

$1 \mathrm{hr}$ - The maximum concentration output by SAILS for any aircraft on the MTR segment was doubled to account for the possibility of two aircraft passing directly over the same receptor in a 1-hour period.

$3 \mathrm{hr}$ - Assumed to be one-half the maximum 1-hr concentration.

$8 \mathrm{hr}$ - Assumed to be one-third the maximum 1-hr concentration.

$24 \mathrm{hr}$ - Assumed to be one-fourth the maximum 1-hr concentration.

Annual - Summation of the highest 1-hr concentrations output by SAILS for all annually scheduled flights, divided by $8,760 \mathrm{hr} /$ year, multiplied by one-tenth. 


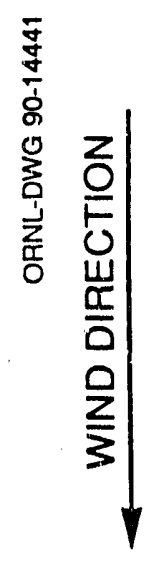
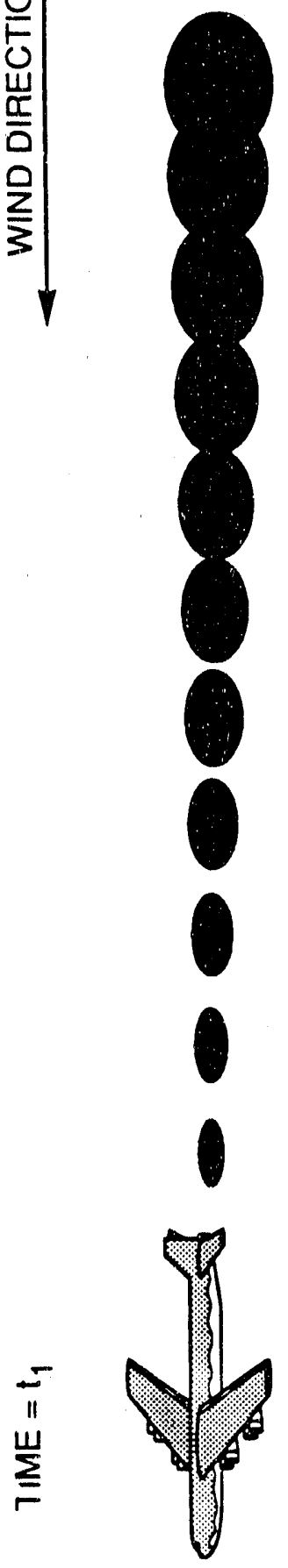
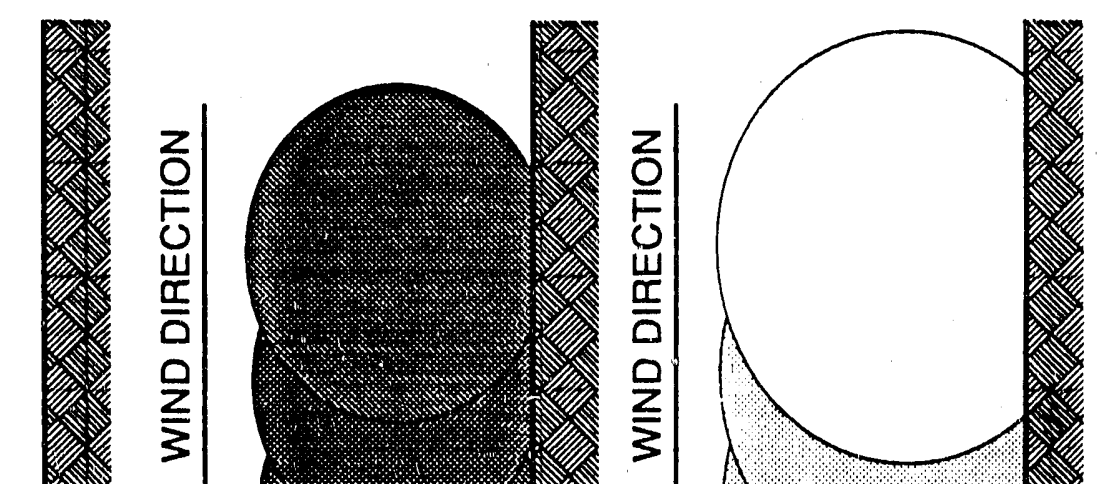
$\checkmark$

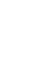
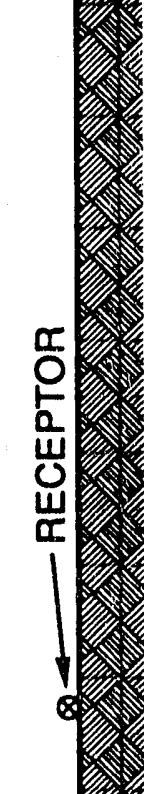

$\stackrel{N}{\stackrel{N}{I I}}$
远 혀월

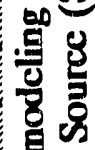
ㅁ․를
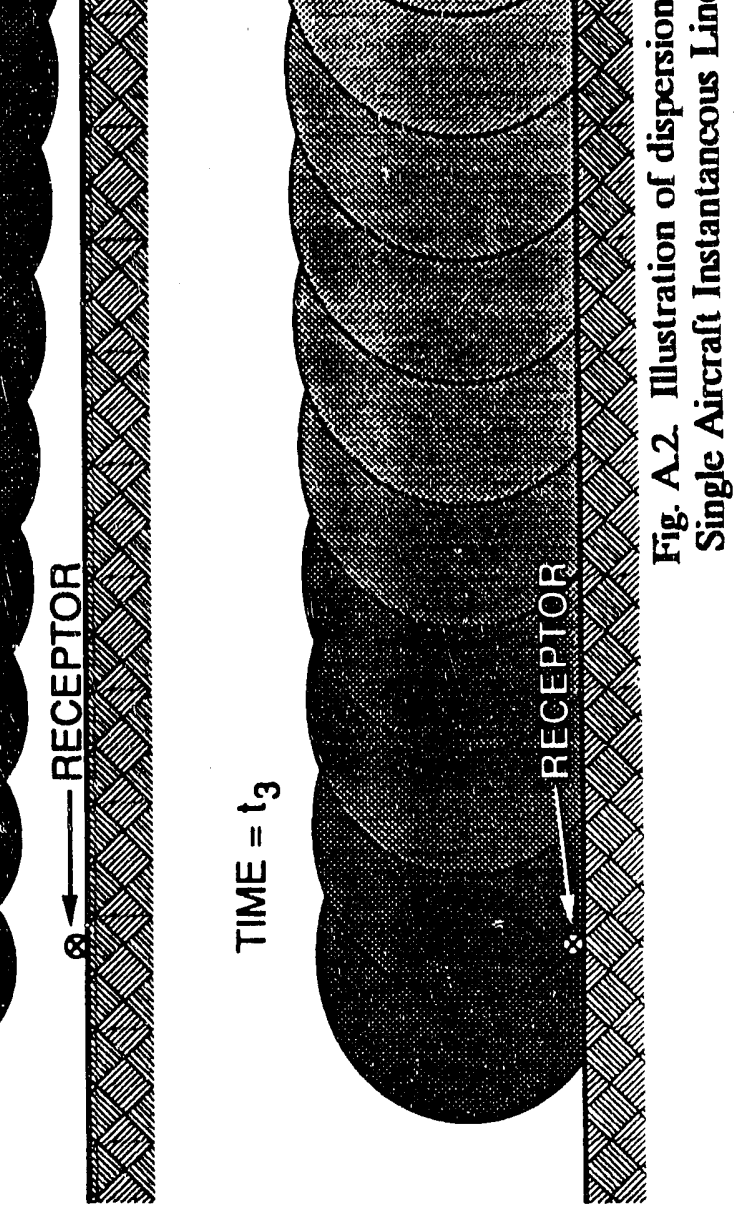
The above assumptions were derived empirically, based on what is known about (1) the horizontal distributions of flight paths relative to the route centerline (Plotkin and Croughwell 1987), (2) variations of vertical aircraft position relative to ground-level, and (3) variations of meteorological conditions over each particular averaging period. The above assumptions are believed to result in quite conservative concentration estimates for averaging periods longer than $1 \mathrm{hr}$, primarily because of the horizontal and vertical variation in aircraft positions on subsequent flights and because of the variability in wind direction over these longer averaging periods. The multiplication factors for obtaining 3-hr, 8-hr, and 24-hr concentrations from the 1-hr concentration are somewhat lower than analogous factors recommended by EPA for continuous elevated point sources (EPA 1977). However, it should be emphasized that the EPA factors were developed for a continuous stationary source, while these factors were developed for an intermittent source, for which each successive emission varies in both horizontal and vertical position relative to a fixed ground-level receptor. For aircraft emissions, the intermittence and spatial variability causes a greater decrease in concentrations for longer averaging periods as compared to stationary point sources.

For predicting impacts under MOAs and RAs, a different modeling approach was taken. Because most flight operations in these airspaces do not follow prescribed routes, it was decided to model these emissions as an area source. The ISCST (EPA 1987) dispersion model was chosen for this exercise since it is a widely used, EPA-approved model and has the capability to simulate impacts from area source emissions.

Although MOA and RA emissions will tend to be distributed over a large portion of thcse airspaces, it is possible that most of the emissions could be concentrated over certain regions of the MOA or RA, such as a strafing area or scoring site. In order to allow for a converging of emissions over a portion of MOAs and RAs, each MOA and RA surface area was divided by four and the emissions of the entire MOA or RA were ascribed to this smaller area. For most of the case study areas, the emissions were modeled as a single area source, which was a square area . required by the ISCST model. However, the Tyndall MOA was modeled as three area surces because of its elongated shape and because sections of this MOA had differing 'ninimum altitude requirements. As with the MTRs, if the minimum altitude for an MOA or RA was listed as "surface" in the airspace database, an altitude of $200 \mathrm{ft}(61 \mathrm{~m})$ was assumed for model input. This assumption will tend to produce conservative concentration estimates for these airspaces since training flight altitudes in these areas vary substantially, more so than for MTRs, with most of the time spent above this altitude.

Rather than try to obtain site-specific or near-site meteorological data for model input for each of the MOAs and RAs, a year of hourly data from a single National Weather Service station (the Greater Cincinnati Airport station) was used for all the ISCST model runs. Although the use of data from this site results in some inaccuracies, the degree of over or under prediction of concentrations is expected to be generally less than a factor of two. As indicated by the results, errors of this magnitude were not of concern, given the low altitude of predicted air quality impacts from MOAs and RAs and the conservative assumptions made in the analysis.

The airspace database contains data describing the hours of scheduling for each airspace. Most of the MOAs and RAs in the case study group had scheduling times which restricted their use to less than $24 \mathrm{hrs}$ day. Most of these airspaces are used primarily in the daylight hours, with 8-12 hr of scheduling time. In order to more accurately simulate the on/off character and timing of these emissions, the ISCST model was executed with the hourly emission rate scalars option. The instantaneous emission rates $(\mathrm{g} / \mathrm{s})$ input to 
ISCST for each run were calculated accordingly, based on the total annual time of scheduled airspace operation. For example, if an MOA was scheduled for use $12 \mathrm{hr} /$ hay, 365 days/year, the annual average emission rate $(\mathrm{g} / \mathrm{s})$ would be doubled to simulate the average emissions over the 36512 -hr periods. The scalars option in ISCST allows the user to turn the emissions on or off (or multiply them by a fraction) for each hour of the day. Thus, in the above example, the scalar would be set to 1.0 for each of the $12 \mathrm{hr}$ during which MOA operations are scheduled and 0.0 for the $12 \mathrm{hr}$ when MOA operations are not scheduled.

\section{A.3.1.2 Visibility impact assessment}

From a technical standpoint, the approach taken to perform the visibility impact analysis was very simple. It consisted of human observations and photographs of aircraft engine exhaust plumes during low-level flight operations. Unfortunately, regulatory agencies (e.g., EPA) have not developed specific quantitative measures to determine what constitutes a significant or adverse impact. Rather, the EPA has stated in its regulations that this determination must be made on a case-by-case basis and must consider the "geographic extent, intensity, duration, frequency and time of visibility impairment ..." (40 CFR Pt. 52.21). Thus, the assessment of potential visibility impacts focused on making human observations and taking photographs of visible exhaust plumes to determine such things as intensity and duration of the visibility impairment. The other parameters which EPA says must be considered in this determination can be inferred from the data contained in the airspace database or other readily available data.

\section{Choice of study site}

The pollutant from aircraft engines most likely to produce visible emissions is particulate matter, although $\mathrm{NO}_{x}$ (in the form of nitrogen dioxide, an orange/brown colored gas) and unburned hydrocarbon vapors could also contribute to a visible plume. Previous observations by a number of individuals have indicated that older aircraft, such as the B-52, create the most visible plumes and that these plumes tend to be black, indicating that smoke (particulate matter) is probably responsible for the visibility of the plumes. This deduction seems reasonable, since newer engines have not only been designed to burn fuel more efficiently but are also subject to standards for control of air pollutant emissions, including smoke or particulate matter (40 CFR Pt. 87). A listing of pollutant emissions data contained in ORNL's database also indicated that the two B-52 models still in use (B-52G and B-52H) have higher particulate matter emissions than any other aircraft in the database.

Based on the above information, it was determined that a B-52 exhaust plume would provide a WC scenario in terms of visibility impact. A scheduled radar-siting exercise in north-central South Dakota, near the town of Eureka, was chosen for evaluation of B-52 exhaust plumes. This exercise involved low altitude B-52 maneuvers similar to those which occur on MTRs. A low altitude MTR near Dickinson, North Dakota, was chosen for additional B-52 and B-1B (a newer large bomber) observations. However, no observations were obtained on this MTR during the field visit, since the scheduled flights were cancelled. Besides providing the opportunity for observing B-52s on low altitude maneuvers, the northern Great Plains were considered ideal for exhaust plume observations because the terrain is relatively flat or gently rolling, the area is sparsely populated with relatively few pollutant sources, and the low relative humidities 
contribute to very good visibility on most days. Thus, the area provides a relatively clear, pristine atmosphere for making observations of aircraft plumes.

\section{Observational procedures}

The aircraft exhaust plume observations and photographs were taken by an ORNL air quality meteorologist. A standard form (see Attachment 2) developed specifically for this study was completed for each overflight observed. This form was developed to provide a complete description of the plume-observer geometry and of those meteorological conditions which might affect the degree and duration of plume perceptibility.

The camera used for the exhaust plume photographs was a $35 \mathrm{~mm}$ Minolta Maxim 9000 using a $28-85 \mathrm{~mm}$ zoom lens. The zoom feature was used primarily for more distant shots to obtain a slightly larger plume image. A program back was installed on the Maxim 9000 to allow imprinting of the time (hr: min: s) on each frame, providing for documentation and later analysis of the rate of visible plume dissipation. Kodacolor Gold ISO-400 film was used for all exhaust plume photographs.

\section{A.3.2 Results}

\section{A.3.2.1 Ambient air quality impact assessment}

Case study impacts

The results of the air quality assessment for the case study airspaces were summarized by classifying the maximum predicted concentrations for each pollutant and averaging time according to the percentage of the NAAQS, PSD Class II increments, and PSD Class I increments represented by the impacts. Four level-of-impact (LOI) categories were defined for the classification of the predicted air quality impacts. The four LOIs were defined as follows:

(1) Predicted incremental concentration is less than $5 \%$ of the applicable NAAQS or PSD increment.

(2) Predicted incremental concentration is $5-50 \%$ of the applicable NAAQS or PSD increment.

(3) Predicted incremental concentration is $50-100 \%$ of the applicable NAAQS or PSD increment.

(4) Predicted incremental concentration exceeds the applicable NAAQS or PSD increment.

The LOIs predicted for the case study airspaces are listed in Table A.2. No column is provided for Res ricted Area 2905 since this area is used only to launch small target drones, which wrould have very minor air pollutant emissions. Note that only a single row is used, for exampie, to show the LOIs with respect to the NAAQS for $\mathrm{SO}_{2}$, even though the are three separate NAAQS (3-hr, 24-hr, and annual) for this pollutant (see Tauic A.1). In cases where NAAQS or PSD increments have been promulgated for multiple averaging periods for a pollutant, the highest LOI category predicted for any of the averagin ? Jeriods was listed in Table A.2. 


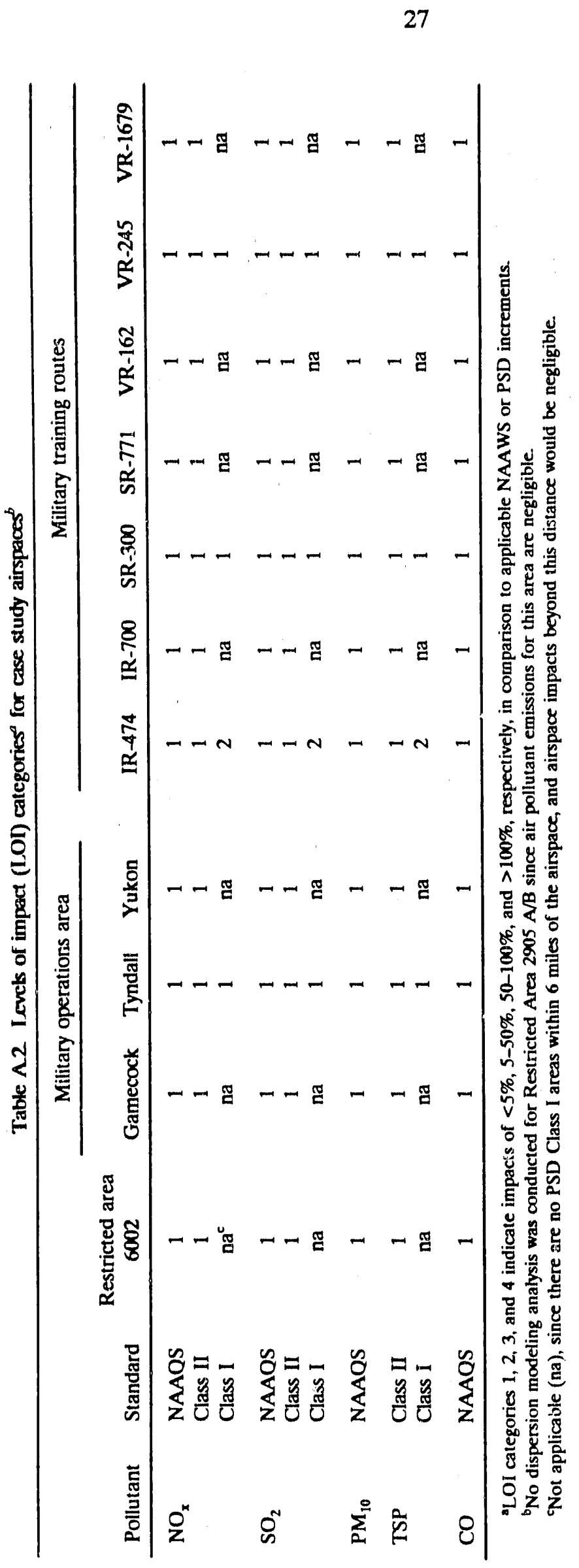


A couple of general statements can be made regarding the results of the air quality impact analysis for the case study group of airspaces. One is that for RAs and MOAs the air quality impacts are insignificant ( $<5 \%$ of any applicable standard; see Sect. A.5) for all pollutants with respect to all standards, even the stringent PSD Class I increments. Another result is that air quality impacts for all airspace types were predicted to be insignificant with respect to all NAAQS and PSD Class II increments. The only potentially significant air quality impacts were predicted for MTRs with respect to PSD Class I increments, and the pollutant of greatest concern with respect to PSD Class I increments was found to be $\mathrm{NO}_{2}$.

The busiest route segments along four of the MTRs were predicted to have potentially significant impacts with respect to a PSD Class I increment for one or more pollutants. These MTR segments were associated with IR-474 over southern Montana, IR-700 over northern New York, SR-300 over northern California, and VR-245 over southern Arizona. In none of these cases did the route segment having the most impact pass over a Class I area, but VR-245 passes very near a Class I area. However, other segments of IR-474 and SR-300 do intersect Class I areas. The impacts of these route segments were assessed to determine their potential contributions over the Class I areas.

A portion of IR-474 skims the northern edge of the Northern Cheyenne Indian Reservation in southern Montana, which has been redesignated as a PSD Class I area. (The original Class II designation of this area under the CAA amendments of 1977 was changed.) Although the centerline of IR-474 does not cross directly over the reservation, the established route width is 4 nautical miles either side of centerline. Thus, some flights using IR-474 could pass over this Class I area. Based on the flight schedule data in the ORNL database, there were 66 flights per month scheduled on the segment of IR. 474 which passes over the edge of the reservation. The air quality analysis indicated that the maximum incremental concentrations of TSP, $\mathrm{SO}_{2}$, and $\mathrm{NO}_{2}$ along this segment of IR-474 could be $5-50 \%$ of the PSD Class I increments for these pollutants. These impacts are considered to be potentially significant, depending on the extent of Class I increment consumed in this area by other pollutart sources in the region.

The route centerline of SR-300 passes just north of, but within 1 mile of, the Mokelumne Wilderness in central California. The Mokelumne Wilderness is a PSD Class I area according to the criteria listed in the 1977 CAA amendments. Because the width of SR-300 is 5 nautical miles either side of the centerline, the route corridor overlays a large part of the Mokelumne Wilderness. The maximum predicted incremental concentrations along this route segment were less than $5 \%$ of the allowable Class I increments for TSP, $\mathrm{NO}_{2}$ and $\mathrm{SO}_{2}$. Therefore, the air quality impacts along the entire extent of SR-300 are expected to be insignificant with respect to all NAAQS and PSD Class II and Class I increments.

The WC route-centerline level of impact along any segment of VR-245 was between 5 and 50\% of the PSD Class I 24-hr TSP increment. Although no PSD Class I areas exist. under VR-245, the Mazatal Wilderness Area, a PSD Class I area, is only about $0.8 \mathrm{~km}$ ( 0.5 mile) from the edge of VR-245. However, air quality impacts along the WC segment of VR-245 were primarily a result of traffic from concurrent routes. These concurrent routes do not continue on the portion of VR-245 near the Mazatal Wilderness. Impacts directly beneath the VR-245 segment near the Mazatal Wilderness were predicted to be less than 5\% with respect to all PSD Class I increments. Thus, the air quality impacts from VR-245 and concurrent routes are considered to be negligible with respect to all NAAQS and PSD increments. 
In summary, the air quality impacts associated with 11 of the 12 case study airspaces were predicted to be less than 5\% of the applicable NAAQS or PSD increments for the areas crossed by these airspaces. The maximum predicted impacts along the busiest segments of several MTRs were greater than 5\% and less than $50 \%$ of the allowable PSD Class I increments. None of these busiest route segments actually crossed over a Class I area. However, a less used segment of IR-474 did intersect a PSD Class I area, the Northern Cheyenne Indian Reservation in southeastern Montana. The maximum predicted incremental TSP, $\mathrm{SO}_{2}$, and $\mathrm{NO}_{2}$ concentrations along this segment of IR-474 were between 5 and 50\% of the PSD Class I increments for these air pollutants. These impacts are considered to be potentially significant, depending on the extent of Class I increment consumption by other sources in the vicinity of this area.

\section{Maximurn concurrent impacts}

On an airspace scale, cumulative air quality impacts could be a concern where relatively high numbers of aircraft use the same route segment. Based on results from the case study analysis, it was concluded that $\mathrm{NO}_{\mathrm{x}}$ emissions $\left[\mathrm{NO}_{\mathrm{x}}\right.$ consists of nitric oxide (NO) and $\mathrm{NO}_{2}$ ] were of greatest concern for potential local air quality impacts. It was also concluded from the case study analysis that MOA and RA emissions are of little concern when those emissions are distributed as an area source. Obviously, if MOA and RA emissions were concentrated along a particular flight path, the impacts would tend to be higher as with MTRs. Thus, analysis of WC local impacts focused on $\mathrm{NO}_{2}$ impacts in conjunction with MTRs, particularly for those routes where there were a large number of concurrent routes with relatively high emissions.

The aircraft emissions and national low altitude military airspace databases were used to produce a list of all MTRs ranked by the calculated $\mathrm{NO}_{x}$ (as $\mathrm{NO}_{2}$ ) emissions per unit length of route. Several of the routes having the highest emissions per unit length were inspected on the Area Planning AP/1B Charts showing MTRs to determine if any of these routes had concurrent route segments. After summing the missions for some of the concurrent route segments it became apparent that the segment with the greatest combined $\mathrm{NO}_{x}$ emissions per unit length was associated with several converging routes over west-central Nevada, near the town of Fallon.

Maximum potential $\mathrm{NO}_{2}$ impacts under the above route segment were estimated using the SAILS dispersion model and the methodology described in Sect. A.3.1.1. All $\mathrm{NO}_{\mathrm{x}}$ emissions were conservatively assumed to be in the form of $\mathrm{NO}_{2}$. The maximum predicted annual $\mathrm{NO}_{2}$ concentration was $1.4 \mu \mathrm{g} / \mathrm{m}^{3}$, which is $1.4,5.6$, and $56 \%$ of the corresponding NAAQS, PSD Class II increment, and PSD Class I increment, respectively.

There are no PSD Class I areas near this route segment and it is highly unlikely that such a high activity airspace would he established over or very near a Class I area in the future. Based on the air quality significance of impact criteria (Sect. A.5), the predicted impact is insignificant $(<5 \%)$ with respect to the NAAQS. The impact is barely over the $5 \%$ threshold for potential signific ance with respect to the PSD Class II increment. However, because of the conservative modeling assumptions (see above and Sect. A.3.1.1), it is expected that maximum $\mathrm{NO}_{2}$ concentrations would be insignificant $(<5 \%)$ even with respect to the PSD Class II increment. 


\section{National impacts}

The estimated national total low altitude emissions for the three categories of airspaces were compared with the total estimated annual man-made pollutant emissions for the nation (EPA 1988) as shown in Table A.3. The comparison indicates that for all pollutants, the nationwide percentage of air pollutants emitted into the lower atmosphere by low altitude military flight operations is well below $1 \%$. Given the very low contribution of low altitude flight emissions to national emissions, the cumulative impacts of these aircraft emissions with regard to regional and national air pollutant problems (e.g., acid rain, regional haze) is clearly ins gnificant.

\section{A.3.2.2 Visibility impact assessment}

The results of the visibility impact assessment indicated that B-52 visible exhaust plumes dissipate quite rapidly. Sequential photographs of a fixed location during and after aircraft passage showed that the time required for the exhaust plume to become invisible ranges from 4 to $19 \mathrm{~s}$. These data were obtained from nine separate photo sequences, each focusing on a fixed background. The angles between the flight path and the photo direction ranged from approximately $30^{\circ}$ to $90^{\circ}$ (perpendicular) for the 9 sequences. In all cases the background was a cloudless sky. In some cases the background sky appearance was deep blue, when the plane passed very near the observer $[<500 \mathrm{ft}$ $(<152 \mathrm{~m})]$ and the photo elevation angle was relatively high. In other cases, the background sky was a lighter, hazy blue, when the exhaust plume was photographed nearer the horizon. The longer observed dissipation times tended to occur with the latter sky background.

The results of the B-52 exhaust plume observations indicated that visible plumes from these aircraft were quite short-lived and are not much more of a visible intrusion than the aircraft itself. Because the B-52s are considered to have the greatest visible exhaust impact of any military aircraft now in use, it is not expected that visible exhaust emissions will have a significant, adverse impact for any low altitude airspace. Also, because newer aircraft engines are generally more efficient and cleaner burning, and most new engines are subject to smoke emission standards, it is expected that as older aircraft such as the B-52 are eventually phased out, visible smoke plumes will become even less noticeable.

\section{A.4 FINDINGS}

This section addresses how the results of the air quality impact analysis can be used for mitigation and policy planning with respect to the establishment of future low altitude airspaces. Only ambient air quality impacts are addressed, since visibility impacts were determined to be an insignificant issue with respect to all aircraft engine exhaust emissions.

\section{A.4.1 Findings Directed at Impacts and Mitigations}

Based on the case study analysis, it appears that air quality is a potential concern for MTRs but not for MOAs and RAs. For MTRs, the concern would seem to be limited to PSD Class I areas (primarily Nationai Parks and National Wilderness Areas). The 


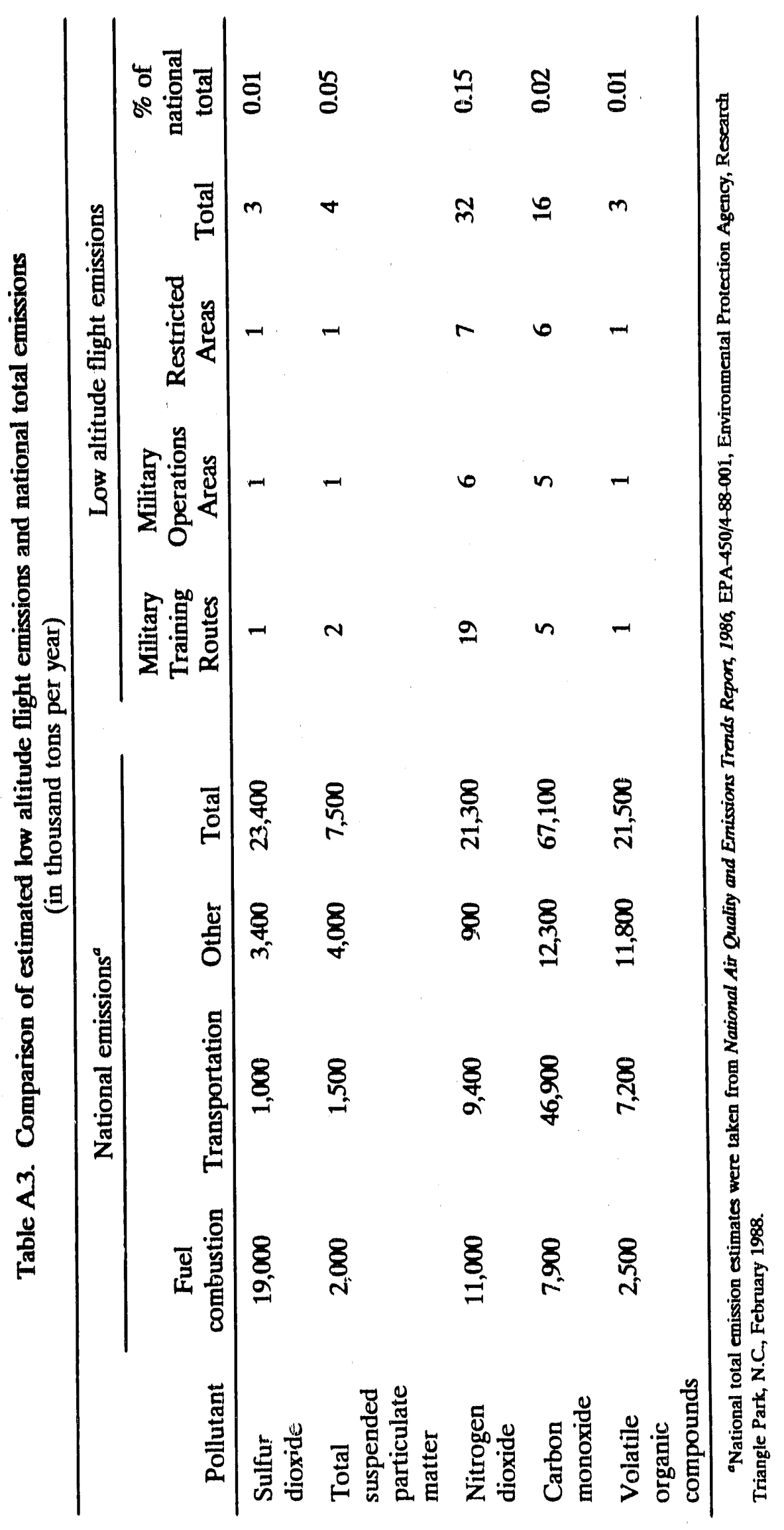


maximum predicted impacts over the highest emission signents of some MTRs were between 5 and $50 \%$ of the allowable Class $I$ increments. Thus, if one of these busier route segments crossed a Class I area, the air quality impacts would be potentially significant. This determination would depend on the amount of PSD Class I increment already consumed by other pollutant sources. Mitigation or prevention of these potentially significant impacts could be accomplished by

1. placing restrictions on the aircraft types allowed to fly over Class I areas;

2. reducing the frequency of flights over Class I areas; or

3. requiring a higher minimum altitude for MTR segments passing over Class I areas.

Based on the emissions and flight frequency data for existing aircraft and airspaces, an MTR segment near Fallon, Nevada, is expected to have the greatest potential for cumulative or concurrent air quality impacts. Dispersion model results indicated that, with the established $200-\mathrm{ft}(61-\mathrm{m})$ minimum altitude for this segment, approximately $50 \%$ of the PSD Class I NO $\mathrm{N}_{2}$ increment could the consumed if this MTR segment passed over a Class I area. Further iterative model runs indicated that if an altitude of at least $800 \mathrm{ft}(244 \mathrm{~m})$ were required for this WC MTR segment, air quality impacts would be insignificant $(<5 \%)$ with respect to PSD Class I increments.

\section{A.4.2 Findings Directed at Policy and Planning Intervention}

Although restrictions on MTR operational parameters can successfully mitigate all potentially significant air quality impacts of future actions, a broader policy implementation could also accomplish this. This policy could consist of the following precautionary measures:

(1) Avoid siting any new MTRs over Class I areas.

(2) Avoid increases in numbers of scheduled flights or decreases in minimum altitudes for any existing MTR segments which intersect Class I areas.

\section{A.4.3 Findings Directed at General Explanations of Impacts}

Ground-level air quality impacts from low-level training flights are essentially proportional to the linear density of emissions along the flight path. The linear density of emissions over a particular time period depends on the aircraft speed, the pollutant emission rate of the aircraft, and number of sorties occurring within the time period. Therefore, restriction of aircraft type and/or number of sorties over a Class I area could minimize emissions such that impacts would be negligible. Also, ground-level air pollutant concentrations will decrease roughly by the inverse square of the emissions release height, if not more. For example, a doubling of the release height would reduce ground-level concentrations by at least a factor of four. Thus, a modest increase in the minimum altitude for an MTR segment would result in relatively large decreases in potential ground-level air quality impacts. 


\section{A.5 DEGREE OF SIGNIFICANCE}

\section{A.5.1 Ambient Air Quality Impacts}

The degree to which air quality impacts from a proposed pollutant source are considered significant depends on (1) the level of those impacts with respect to air quality standards, or other levels set to protect the environment and (2) the existing levels of pollutant concentrations in an area that the new source would impact. For example, if a proposed source caused an increase in $\mathrm{SO}_{2}$ concentration equivaient to $20 \%$ of the annual average NAAQS in an area where existing concentrations were already $90 \%$ of the NAAQS, this would be judged a significant impact. On the other hand, if existing levels of $\mathrm{SO}_{2}$ were equal to $120 \%$ of the NAAQS and the new source was predicted to contribute an additional $0.1 \%$ of the NAAQS, this would be judged as a trivial or insignificant impact on the part of the new source.

The EPA has established rules and procedures for determining what levels of new source impact are considered potentially significant. A new source or source modification is generally considered to have an insignificant impact on ambient air quality if it contributes less than certain concentration thresholds (see 40 CFR Pt. 51.167 for a listing of the threshold values by pollutant). These thresholds established by EPA are generally about 5\% of the lesser of the NAAQS or PSD Class II increment (see Table A.1) for each pollutant and averaging time. Thus, for example, a source which is predicted to cause a 1 -hr CO impact of $1 \mathrm{mg} / \mathrm{m}^{3}\left(2.5 \%\right.$ of the 1 -hr NAAQS for CO of $\left.40 \mathrm{mg} / \mathrm{m}^{3}\right)$ in an area where existing $\mathrm{CO}$ levels are over the NAAQS, would be considered an insignificant contributor to the total CO level.

Based on the above precedent, the following LOIs were defined for the GEIS air quality impact analysis:

(1) Negligible impact-Predicted incremental concentrations of the pollutant of concern are less than 5\% of the applicable NAAQS or allowable PSD increment. Because the impact of the new source is minor, a cumulative impact assessment which takes into acrount existing pollutant concentrations is unnecessary.

(2) Low impact--Predicted incremental concentrations of the pollutant of concern are from 5 to $50 \%$ of the applicable NAAQS or allowable PSD increment. A cumulative impact assessment is needed to determine if the incremental plus background (existing) concentrations would exceed the NAAQS or PSD increments. Mitigating measures need to be considered if total impacts exceed NAAQS or PSD increments.

(3) Moderate impact-Predicted incremental concentrations of the pollutant of concern are from 50 to $100 \%$ of the applicable NAAQS or allowable PSD increment. A cumulative impact assessment is needed to determine if the incremental plus background concentrations would exceed the NAAQS or PSD increments. Mitigating measures need to be considered if total impacts exceed NAAQS or PSD increments and should be considered in any case.

(4) High impact-Predicted incremental concentrations of the pollutant of concern are over the applicable NAAQS or allowable PSD increment. A cumulative impact assessment is needed to determine the extent to which total concentrations exceed NAAQS or PSD increments. Mitigating measures are needed to reduce total concentrations to acceptable levels. 
If the LOI is within category 1 , the air quality impact of the new source is judged to be insignificant, regardless of the existing air quality in the area to be affected. If the LOI is within category 2 or 3 , the impact of the new source is judged to be significant if it contributes (cumulatively) to a predicted exceedance of NAAQS or PSD increments. If the LOI is within category 4 , the new source impact is considered significant by itself, even before the consideration of cumulative impacts.

\section{A.52 Visibility Impacts}

Because there have been no quantitative standards or measures established to determine what intensity, frequency, or duration of visibility impairment is significant, the criteria for such determination for this analysis were based on the judgement of an experienced air quality analyst. EPA regulations (40 CFR Pt. 52.21) state that the determination of whether a source causes adverse impact on visibility should be made on a case-by-case basis. It is assumed here that "adverse" and "significant" are synonymous.

As stated earlier, the CAA amendments of 1977 established that visibility is a concern only with respect to Class I areas, primarily for aesthetic reasons. Visible exhaust plumes which persist for some time after aircraft passage could be considered to have a significant impact on visibility. It was determined subjectively that for this analysis, if a plume were visible at one point in space for more than $30 \mathrm{~s}$, it would constitute a potentially significant impact. The rationale for this subjective sriteria is as follows. The aircraft itself can constitute an intrusion into the visitor's visual experience of the Class I area. In fact, because of the audible and visual impact of a low altitude training flight, the visitor is likely to keep his or her vision fixed on the aircraft, just for curiosity, if nothing else. Only after an aircraft has passed from view or is at some distance is the visitor likely :o re-focus on the original field of view (e.g., a scenic vista). If a visible plume of material is still apparent at that time, the visitor may consider this an additional intrusion on the visual experience. However, if all visible traces of the plume are gone at this point, it can probably be concluded that any visible exhaust emissions were no more of a visual impact than the aircraft itself.

Although a period of $30 \mathrm{~s}$ is somewhat arbitrary for this determination, it corresponds to approximately 3-4 miles of flight distance for the typical aircraft speeds used on low altitude training missions. 


\section{A6 REFERENCES}

Bjorklund, J. R., C. R. Bowman, and G. C. Dodd, n.d. User Guide-Forest Service Aerial Spray Compute- Model-FSCBG-2 (Review Draft), FPM 88-5, USDA Forest Service, Forest Pest Management, Davis, Calif.

Defense Mapping Agency 1988. Area Planning AP/1B Chart, Military Training Routes (Eastern U.S., Central U.S., Western U.S.), Defense Mapping Agency Aerospace Center, St. Iouis, Mo. Effective 5 May 1988-30 June 1988.

Dumbauld, R. K., J. R. Bjorklund, and S. F. Saterlie 1980. Computer Models for Predicting Aircraft Spray Dispersion and Deposition Above and Within Forest Canopies: User's Manual for the FSCBG Computer Program, 80-11, USDA Forest Service, Forest Pest Management, Davis, Calif.

EPA (U.S. Environmental Protection Agency) 1977. Guidelines for Air Quality Maintenance Planning and Analysis Volume 10 (Revised): Procedures for Evaluating Air Quality Impact of New Stationary Sources, EPA-450/4-77-001, EPA, Research Triangle Park, N.C.

EPA (U.S. Environmental Protection Agency) 1979. Protecting Visibility: An EPA Report to Congress, EPA-450/5-79-008, U.S. Environmental Protection Agency, EPA, (NTIS No. PB 80-220320) Research Triangle Park, N.C.

EPA (U.S. Environmental Protection Agency) 1980. Workbook for Estimating Visibility Impairment, EPA-450/4-80-031, EPA, (NTIS No. PB 81-157885) Research Triangle Park, N.C.

EPA (U.S. Environmental Protection Agency) 1982. PTPLU $\rightarrow$ A Single Source Gaussian Dispersion Algorithm, EPA-600/8-82-014, EPA, (NTIS No. PB 83-211235) Research Triangle Park, N.C..

EPA (U.S. Environmental Protection Agency) 1985. Compilation of Air Pollutant Emission Factors, Volume 2: Mobil Sources, 4th ed., AP-42, EPA, (NTIS No. PB 87-205266) Research Triangle Park, N.C.

EPA (U.S. Environmental Protection Agency) 1986. User's Network for Applied Modeling of Air Pollution (UNAMAP), version 6 (computer programs on tape), National Technical Information Service, (NTIS No. PB 86-222361) Springfield, Va.

EPA (U.S. Environmental Protection Agency) 1987. Industrial Source Complex (ISC) Dispersion Model User's Guide-Second Edition (Revised), EPA-450/4-88-002, EPA, Research Triangle Park, N.C.

EPA (U.S. Environmental Protection Agency) 1988. National Air Quality and Emissions Trends Report, EPA-450/4-88-001, EPA, Research Triangle Park, N.C.

Lorang, P. 1978. Review of Past Studies Addressing the Potential Impact of CO, HC, and $\mathrm{NO}_{x}$ Emissions from Commercial Aircraft on Air Quality, U. S. Environmental Protection Agency (NTIS Publication No. PB 286 421), Ann Arbor, Mich.

Miller, C. O. M. 1980. "A Mathematical Model of Aerial Deposition of Pesticides from Aircraft," Environmental Science and Technology 14, 824-31. 
Platt, M. et al., 1988. "An Emissions Database for U.S. Navy and Air Force Aircraft Engines," paper submitted to ASME International Gas Turbine and Aeroengine Congress and Exposition, June 5-9, 1988, Amsterdam, the Netherlands.

Plotkin, K. J. and E. P. Croughwell 1987. Environmental Noise Assessment for Military Aircraft Training Routes, Volume 1: SAC Low-Level Routes, Report No. AAMRLTR-87-0001, Armstrong Aerospace Medical Research Laboratory, Wright-Patterson AFB, Ohio.

Seitchek, G. D. 1985. Aircraft Engine Emissions Estimator, ESL-TR-85-14, Air Force Engineering and Services Center, Tyndall AFB, Fla.

Shelton, E. M. 1976. Aviation Turbine Fuels, 1975, U.S. Energy Research and Development Administration, BERC/PPS-76/2, Bartlesville Energy Research Center, Bartlesville, Okla.

Slade, D. H. (ed.) 1968. Meteorology and Atomic Energy, prepared by Air Resources Laboratory, Environmental Sciences Services Administration, for the U.S. Atomic Energy Commission (NTIS Publication No. TID-24190).

Williams, M. D., E. Treiman, and M. Wecksung 1979. The Simulated-Photograph Technique as a Tool for the Study of Visibility Impairment, LA-8105-MS, Los Alamos Scientific Laboratory, Los Alamos, N.M. 
$37 / 38$

ATTACHMENT 1

LISTING OF SAILS MODEL FORTRAN CODE AND SAMPLE MODEL OUTPUT 
C SINGLE AIRCRAFT INSTANTANEOUS LINE SOURCE (SAILS) MODEL

C

C VERSION: 1.1, DATED 11/02/89

AUTHOR: EDWARD LIEBSCH, RESEARCH ASSOCIATE, MARTIN MARIETTA ENERGY SYSTEMS, INC.

C

$\mathrm{C}$

DIMENSION ISTAB(49),WS(49),ARR(49),TITLE(20),SC(6),SD(6)

CHARACTER*4 TTTLE

CHARACTER*1 NY

C

C

DATA ISTAB / 7*1,9*2,9*3,14*4,5*5,5*6/

DATA WS / 0.5,0.8,1.0,1.5,20,25,3.0,0.5,0.8,1.0,1.5,20,25,3.0,

$14.0,5.0,2.0,2.5,3.0,4.0,5.0,7.0,10.0,120,15.0,0.5,0.8,1.0,1.5,2.0$

$2,25,3.4 ., 5.7 ., 10 ., 12,15 ., 20 ., 2,25,3 ., 4 ., 5.2,2,5,3 ., 4.5 .11$

DATA SC,SD / 24.1667,18.333,125,8.333,6.25,4.1667,2.5334,1.8096,

C

1 1.0857,.72.382.54287,.36191/

C

OPEN (8,FILE = 'SAILS.OUT)

WRITE $(*, 900)$

WRTTE(",901)

READ(*,902) (TITLE(I),I=1,20)

10 WRTTE $(*, 904)$

READ(“,905) RHT

WRTTE(".909)

C

C READ INVERSION HEIGHT. THE INVERSION HEIGHT MUST BE GREATER

C THAN THE RELEASE HEIGHT OR THE GROUND-LEVEI CONCENTRATION IS

C ASSUMED TO BE NEGLIGIBLE RE-PROMPT FOR INVERSION HEIGHT IF

C A VALUE LESS THAN OR EQUAL TO THE RELEASE HEIGHT W.AS ENTERED.

C

20 READ (*,910) AMH

IF(AMH .GT. RHT) GOTO 30

WRITE $(*, 913)$

GOTO 20

30 WRITE $(*, 914)$

READ(*,915) QPRIME

WRITE $(*, 919)$

READ $(*, 920)$ AS

WRTTE $(*, 924)$ RHT,AMH,QPRIME,AS

WRTE $(*, 925)$

READ $(*, 926) \mathrm{NY}$

IF(NY .EQ. 'N' .OR. NY .EQ. 'n') GOTO 10

WRITE $(8,930)$

WRTTE(8,931) TITLE

WRTE(8,924) RHT,AMH,QPRIME,AS

WRITE(",927)

C SPECIFY PORTION OF LINE SOURCE TO BE MODELED AS A DISCRETE PUFF 
C IN UNTTS OF METERS.

PL $=100$.

C CONVERT AIRCRAFT AIRSPEED FROM MILES/HR. TO METERS/SEC.

$A S M=A S^{*} 0.447$

C CONVERT RELEASE HEIGHT AND MIXING HEIGHT FROM FEET TO METERS RHT $=$ RHT 0.3048

$\mathrm{AMHH}=\mathrm{AMH}^{*} 0.3048$

$A M H I=1.0 / \mathrm{AMH}$

C CONVERT EMISSION RATE FROM LB/HR TO GRAMS/SEC

QPRIME = QPRIME*0.126

C COMPUTE THE MASS OF ONE PUFF IN GRAMS $Q=Q P R I M E * P L / A S M$

C BEGIN LOOP OVER ALI. STABIITYYWIND SPEED COMBINATIONS DO $200 I=1,49$

C COMPUTE THE NUMBER OF PUFFS WHICH PASS A CENTERLINE RECEPTOR

C IN A ONE-HOUR PERIOD

NPUFF $=W S(I) * 3600 . / P L+0.5$

UBARI $=1.0 / W S(I)$

$X=0.0$

SPSI $=0.0$

IST $=$ ISTAB(I)

C BEGIN LOOP OVER PUFFS

DO $100 \mathrm{~J}=1$,NPUFF

$\mathrm{PX}=\mathrm{J}-0.5$

$X=P L * P X$

$\mathrm{XK}=.001 * \mathrm{X}$

C COMPUTE SIGMA-Y

$T H=.017453293^{*}($ SC(IST)-SD(IST)*ALOG(XK))

SIGY $=465.11628^{*} \mathrm{XK}^{*} \mathrm{TAN}(\mathrm{TH})$

SIGYI $=1.0 /$ SIGY

C CALI SUBROUTINE TO COMPUTE SIGMA-Z

CALL SIGMAZ(XK,SZ,IST)

SIGZI $=1.0 / 5 Z$

C CHECK IF SIGMA-Z IS LARGE COMPARED TO MIXING HEIGHT

C IF SO, ASSUME UNIFORM VERTICAI MIXING

C

IF(SZ .GE 1.6*AMH) GOTO 50

C SALCULATE VERTICAL TERM (V)

$V=0.0$

$A 2=0.0$

$40 \mathrm{VL}=\mathrm{V}$

$A 2=A 2+20$

HMA2 $=A 2 * A M H$

$A 3=($ HMA2-RHT) $*$ SIGZI

$A 4=($ HMA2 + RHT $) *$ SIGZI

$A 3=-5^{*} A 3^{\circ} \mathrm{A3}$

$A 4=.5^{*} \mathrm{~A} 4^{*} \mathrm{~A} 4$

$A S=0.0$

IF(A3 .GT. -38.) $A 5=\operatorname{EXP}(A 3)$ 
$\mathrm{A} 6=0.0$

$\operatorname{IF}(A 4$.GT. -38.) $A 6=\operatorname{EXP}(A 4)$

$V=V+A 5+A 6$

IF(ABS(V-VL) .GT. 1.E-8) GOTO 40

$A 2=-.5 *$ RHT ${ }^{*}$ RHT ${ }^{*}$ SIGZI*SIGZI

IF(A2 .GT. -38.) $V=\operatorname{EXP}(A 2)+V$

C EQUATION FOR TOTAL EXPOSURE FROM AN INSTANTANEOUS PUFF

RELEASE

PSI $=318309886^{*} Q^{* S I G Y I * S I G Z I * U B A R I * V}$

GOTO 90

C EQUATION FOR TOTAL EXPOSURE FROM AN INSTANTANEOUS PUFF

RELEASE WTTH

C UNIFORM VERTICAL MIXING

50 PSI $=$ Q*SIGYI*AMHI"UBARI*39894228

$\mathrm{C}$

C SUM EXPOSURE FOR PUFF AND GET ANOTHER PUFF

90 SPSI = SPSI + PSI

100 CONTINUE

C

C CONVERT ONE-HOUR EXPOSURE TO A ONE-HOUR CONCENTRATION

CHI $=$ SPSI 3600.0

$\operatorname{ARR}(\mathrm{I})=\mathrm{CHI}$

200 CONTINUE

C

C WRITE OUTPUT TO FILE

WRITE $(8,933)$

ISTOLD $=1$

DO $300 I=1,49$

IF(ISTAB(I) .NE ISTOLD) WRTTE $(8,935)$

WRITE (8,934) ISTAB(I),WS(I),ARR(I)

ISTOLD $=$ ISTAB(I)

300 CONTINUE

STOP

C

C

900 FORMAT(' THE SAILS MODEL CALCULATES GROUND-LEVEL PLUME-CENTERLINE' 1.j,' CONCENTRATIONS FOR AN ELEVATED INSTANTANEOUS LINE SOURCE WHIC

2H IS',', PARALIEI TO THE WIND DIRECTION. THE MODEL CALCULATES TH 3E CONCEN-' $l, '$ 'TRATIONS FOR AN ARRAY OF WIND SPEED/STABIITTY CONDI 4TIONS. THE',/' CONCENTRATION ESTIMATES ARE CONSIDERED TO BE WORS ST-CASE ONE-HOUR',,' VALUES. THE SAIIS MODEL IS INTENDED AS A "SC 6REENING" MODEL FOR'J,' EMISSIONS FROM LOW-FL YING AIRCRAFT',/II

901 FORMAT' ENTER TITLE, UP TO 80 CHARACTERS (SUGGEST INDICATION OF A 1IRCRAFT, ,' AND/OR ENGINE MODEL, POLLUTANT TYPE, ETC.)', $/,==>')$

902 FORMAT(20A4)

904 FORMAT(' ENTER RELEASE HEIGHT (FEET) $=$ =>')

905 FORMAT(F10.3)

909 FORMAT(' ENTER INVERSION HEIGHT (FEET) ==>')

910 FORMAT(F10.3) 
913 FORMAT(' INVERSION HEIGHT MUST BE LARGER THAN RELEASE HEIGHT')

914 FORMAT(' ENTER AIRCRAFT EMISSION RATE (LB/HR) ==>')

915 FORMAT(F10.5)

919 FORMAT(' ENTER AIRCRAFT AIRSPEED (MILES/HR.) = = >')

920 FORMAT(F10.3)

924 FORMAT(' INPUT DATA' $₫ \ldots \ldots$.....',/, REIEASE HEIGHT =',F10.3

1,' FEET $\checkmark$,' INVERSION HEIGHT $=$ ',F10.3,' FEET,$/$, EMISSION RATE

2 =',F10.3,' LB/HR',', AIRCRAFT AIRSPEED =',F10.3,' MIIES/HR' $/ /$

3/)

925 FORMAT(' ARE THESE DATA CORRECT? $(\mathrm{Y} N \mathrm{~N})==>$ ')

926 FORMAT(A1)

927 FORMAT(' EXECUTION CONTINUING...')

930 FORMAT(25X,'SAILS - VERSION 1.1 (11/2/89)', ,25X,'SINGLE AIRCRAFT

1DNSTANTANEOUS',$/ 25 X$, IINE SOURCE MODEL',//)

931 FORMAT(32X, ***" TITLE ***"//,20A4//)

933 FORMAT(11X,'STABILTY',6X, 'WIND SPEED',5X,'ONE-HR. CONC.',,27X,'(

1M/SEC.)',6X,'(GRAMS/M**3)')

934 FORMAT(14X,12,11X,F6.2,8X,E11.4)

935 FORMAT(' ')

END

C

C SUBROUTINE SIGMAZ CAICULATES THE VERTICAI STANDARD DEVIATION OF

C THE PUFF CONCENTRATION DISTRIBUTION. THE COEFFICIENTS "WERE TAKEN

C FROM THE EPA ISCST MODEL (DATED 88207).

C

SUBROUTINE SIGMAZ(X,SZ,IST)

DDMENSION SASIGZ(38),SBSIGZ(38),X1(10,6),INDSGZ(6)

DATA SASIGZ / 1228,

$1 \quad 158.08,170.22,179.52,217.41,258.89,346.75,2 * 453.85$,

$290.673,98.483,109.3,61.141,34.459,32.093,32.093,33.504,36.65$,

$344.053,24.26$,

$4 \quad 23.331,21.628,21.628,22.534,24.703,26.97,35.42,47.61$,

5 15.209,14.457,13.953,13.953,14.823,16.187,17.836,22.651,27.074,

634.219 /

DATA SBSIGZ 1.9447 ,

$\mathrm{X} \quad 1.0542,1.0932,1.1262,1.2644,1.4094,1.7283,2 * 2.1166$,

$1.93198,98332,1.0971, .91465,86974,81066,64403,60486,56589$,

X 51179,8366 ,

$2 \quad 81956,75660,63077,57154,50527, .46713,37615,29592$,

$3.81558, .78407, .68465,63227,, 54503, .46490,41507,32681, .27436$,

421716 /

DATA INDSGZ 10,9,12,13,19,28/

DATA X1 $1.1,15,2,25,3,4,5,3.11,1 . E 20,0 ., 2,4,1 . E 20,7 *^{*} 0$.,

1 1.E20,9*0., 3,1.3, $10 ., 30,1$. E20,4*0., .1,3,1.,2,4.,10.,

$220 ., 40 ., 1 . E 20,0 ., \quad 2,7,1,2,3 ., 7 ., 15 ., 30 ., 60 ., 1 . \mathrm{E} 20 /$

C

$I=1$

IF(IST .EQ. 3) GOTO 20

$10 \mathrm{IF}(\mathrm{X}-\mathrm{X} 1(\mathrm{~L}, \mathrm{IST})$.LE 0.0$)$ GOTO 20 
$\mathrm{I}=\mathrm{I}+\mathrm{I}$

GOTO 10

20 INDXI = INDSGZ(IST) + I

SZ = SASIGZ(INDX1)*X**SBSIGZ(INDX1)

$S Z=A M I N 1(S Z, 5000$.

RETURN

END 
SAIIS - VERSION 1.1 (11/2/89)

SINGLE AIRCRAFT INSTANTTANEOUS

LINE SOURCE MODEL

**** TITLE ****

F-15, NO2 emissions, E Liebsch, 12-12-89

INPUT DATA

RELEASE HEIGHT $=300.000$ FEET

INVERSION HEIGHT $=5000.000$ FEET

EMISSION RATE $=12.544 \mathrm{LB} / \mathrm{HR}$

AIRCRAFT AIRSPEED $=460.000$ MILES/HR

\begin{tabular}{|c|c|c|}
\hline STABחITY & WIND SPEED & ONE-HR. CONC. \\
\hline & (MASEC.) & (GRAMS/M**3) \\
\hline 1 & 0.50 & $0.4367 \mathrm{E}-07$ \\
\hline 1 & 0.80 & $0.2906 \mathrm{E}-07$ \\
\hline 1 & 1.00 & $0.2392 E-07$ \\
\hline 1 & 1.50 & $0.1682 E-07$ \\
\hline 1 & 2.00 & $0.1310 \mathrm{E}-07$ \\
\hline 1 & 2.50 & $0.1080 \mathrm{E}-07$ \\
\hline 1 & 3.00 & $0.9217 E-08$ \\
\hline 2 & 0.50 & $0.7206 \mathrm{E}-07$ \\
\hline 2 & 0.80 & $0.5513 \mathrm{E}-07$ \\
\hline 2 & 1.00 & $0.4678 E-07$ \\
\hline 2 & 1.50 & $0.3370 \mathrm{E}-07$ \\
\hline 2 & 200 & $0.2624 \mathrm{E}-07$ \\
\hline 2 & 250 & $0.2147 \mathrm{E}-07$ \\
\hline 2 & 3.00 & 0.1820 E-07 \\
\hline 2 & 4.00 & $0.1400 E-07$ \\
\hline 2 & 5.00 & 0.1143E-07 \\
\hline 3 & 2.00 & $0.4247 \mathrm{E}-07$ \\
\hline 3 & 250 & $0.3569 E-07$ \\
\hline 3 & 3.00 & 0.3074E-07 \\
\hline 3 & 4.00 & $0.2404 E-07$ \\
\hline 3 & 5.00 & $0.1973 E-07$ \\
\hline 3 & 7.00 & $0.1454 E-07$ \\
\hline 3 & 10.00 & $0.1047 E-07$ \\
\hline 3 & 12.00 & $0.8844 E-08$ \\
\hline 3 & 15.00 & $0.7198 E-08$ \\
\hline
\end{tabular}




\section{$45 / 46$}

1

$\begin{array}{lrl}4 & 0.50 & 0.2193 \mathrm{E}-07 \\ 4 & 0.80 & 0.4245 \mathrm{E}-07 \\ 4 & 1.00 & 0.4827 \mathrm{E}-07 \\ 4 & 1.50 & 0.5238 \mathrm{E}-07 \\ 4 & 2.00 & 0.5050 \mathrm{E}-07 \\ 4 & 2.50 & 0.4222 \mathrm{E}-07 \\ 4 & 3.00 & 0.4384 \mathrm{E}-07 \\ 4 & 4.00 & 0.3792 \mathrm{E}-07 \\ 4 & 5.00 & 0.3325 \mathrm{E}-07 \\ 4 & 7.00 & 0.2662 \mathrm{E}-07 \\ 4 & 10.00 & 0.2053 \mathrm{E}-07 \\ 4 & 12.00 & 0.1784 \mathrm{E}-07 \\ 4 & 15.00 & 0.1495 \mathrm{E}-07 \\ 4 & 20.00 & 0.1181 \mathrm{E}-07 \\ & & \\ 5 & 2.00 & 0.3413 \mathrm{E}-07 \\ 5 & 2.50 & 0.3623 \mathrm{E}-07 \\ 5 & 3.00 & 0.3674 \mathrm{E}-07 \\ 5 & 4.00 & 0.3569 \mathrm{E}-07 \\ 5 & 5.00 & 0.3373 \mathrm{E}-07 \\ & & \\ 6 & 2.00 & 0.8302 \mathrm{E}-08 \\ 6 & 250 & 0.1169 \mathrm{E}-07 \\ 6 & 3.00 & 0.1437 \mathrm{E}-07 \\ 6 & 4.00 & 0.1799 \mathrm{E}-07 \\ 6 & 5.00 & 0.1997 \mathrm{E}-07\end{array}$


ATTACHMENT 2

FORM FOR RECORDING AIRCRAFT EXHAUST PLUME VISIBILITY OBSERVATIONS 


\section{Aircraft Exhaust Plume Observations}

Route/Airspace:

Segment (if MTR):

Location (attach map and photo):

Viewing Direction (if MTR):

Note that this is the direction of the observer's line-of-sight, perpendicular to the expected flight path.

Sky condition (wide angle or fish-eye photo?):

Indicate the total fraction of sky cover (eighths), general cloud heights and the prevalent cloud type(s) (e.g., high thin cirrus, low stratus, etc.). Also indicate presence of any haze, fog, or precipitation in the area.

Visible Range (miles):

Estimate by selecting an unobstructed vantage point and determining the most distant visible object or landmark which can be pinpointed on a map.

Topographic maps of the area are helpful in making this observation.

Date:

Temp. (F)

R.H.

Windspeed (mph)

\begin{tabular}{|c|c|c|c|c|}
\hline Local time & Roll No. & Frame No. & $\begin{array}{l}\text { Flight Path } \\
\text { Photo Angle }\end{array}$ & Comments \\
\hline & & & & \\
\hline & & & & \\
\hline & & & & \\
\hline & & & & \\
\hline & & & & \\
\hline & & & & \\
\hline & & & & \\
\hline & & & & \\
\hline & & & & \\
\hline
\end{tabular}



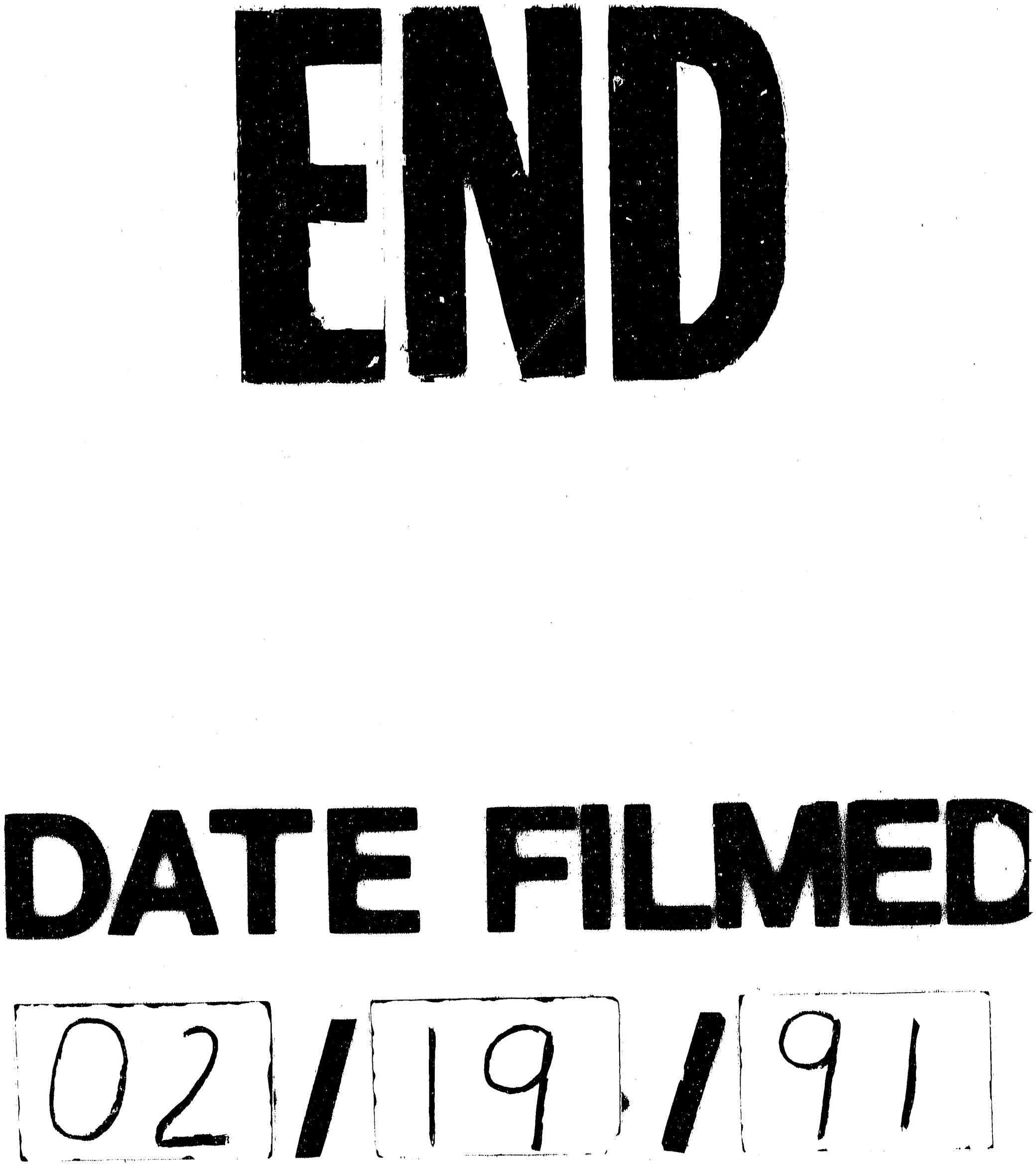